University of Rhode Island

DigitalCommons@URI

Open Access Master's Theses

2013

\title{
AN EMULSION-BASED ROUTE TO GENERATE MAGNETIC CAPSULES FOR CONCRETE APPLICATIONS
}

Lennart Max Kleinfeldt

University of Rhode Island, lennart.max.k@web.de

Follow this and additional works at: https://digitalcommons.uri.edu/theses

\section{Recommended Citation}

Kleinfeldt, Lennart Max, "AN EMULSION-BASED ROUTE TO GENERATE MAGNETIC CAPSULES FOR CONCRETE APPLICATIONS" (2013). Open Access Master's Theses. Paper 167.

https://digitalcommons.uri.edu/theses/167

This Thesis is brought to you for free and open access by DigitalCommons@URI. It has been accepted for inclusion in Open Access Master's Theses by an authorized administrator of DigitalCommons@URI. For more information, please contact digitalcommons-group@uri.edu. 
AN EMULSION-BASED ROUTE TO GENERATE MAGNETIC CAPSULES

FOR CONCRETE APPLICATIONS

BY

LENNART MAX KLEINFELDT

A THESIS SUBMITTED IN PARTIAL FULFILLMENT OF THE

REQUIREMENTS FOR THE DEGREE OF

MASTER OF SCIENCE

IN

CHEMICAL ENGINEERING

UNIVERSITY OF RHODE ISLAND

2013 
MASTER OF SCIENCE THESIS

$\mathrm{OF}$

LENNART MAX KLEINFELDT

APPROVED:

Thesis Committee:

Major Professor Arijit Bose

Richard Brown

Sze C. Yang

Nasser H. Zawia

DEAN OF THE GRADUATE SCHOOL

UNIVERSITY OF RHODE ISLAND

2013 


\begin{abstract}
The deterioration of reinforced concrete structures due to corrosion of the reinforcement bars has a major ecological and economical impact worldwide. Increased corrosion inhibition shall be allowed by placing polyurea capsules containing water-soluble chemicals that protect the steel such as calcium nitrite. The capsules are modified with iron oxide nanoparticles to generate a magnetic susceptibility of the capsules. The iron oxide particles are introduced to the process in the preliminary step of emulsification of the water phase. The magnetic property can be possibly used to attract the capsules by running current through the steel wires which induces a magnetic field around them. The corrosion inhibiting property emerges when necessary after cracks in the concrete matrix penetrate to the steel bars, which facilitates water with dissolved salts to reach the metal surface. The cracks cause the polymer wall of the capsules to break and release the chemicals stored inside. The work presents the route to produce the magnetically modified capsules containing calcium nitrite as corrosion inhibiting compound and gives an outlook on future work. Increased corrosion inhibition in reinforcement bars leading to an extended service life of concrete structures is expected to be highly beneficial for worldwide industry.
\end{abstract}




\section{ACKNOWLEDGMENTS}

I have deep appreciation for my major professor, Dr Arijit Bose, who offered me this interesting project and welcomed me in his group. His guidance has helped me in the time of research and writing of this thesis. I want to thank Dr Richard Brown who agreed to be my co-advisor on my committee. I thank him for the advice concerning the lab equipment and the help with questions. Furthermore, I would like to acknowledge Dr Sze C Yang for being on my thesis committee. Thank you to Dr Sigrid Berka who aided me throughout my exchange experience and serving as the chair on my thesis defense committee.

I express my sincere gratitude to Amitesh Saha for helping me with different experiments, introducing me to the scanning electron microscope, and countless discussions about my research. It has always been a pleasure to discuss ideas with you, which encouraged me to move forward. Additionally, I want to thank my lab mate Indrani Chakraborty for sharing many fun but also serious moments in the lab including the German lessons. Andrew Murphy, thank you for sharing an office with me and the various conversations we had about anything and everything.

Moreover, I would like to say thank you to a few people from the department of Chemical Engineering for their help with my work. Dr Everett E. Crisman for contributing with his knowledge to the quality of my SEM images. Sheryl Girard for always giving me a smile while taking care of the paperwork together with Brenda Moyer. Valuable contribution to setting up my equipment came from Vin Caramadre and Rob D'Ambrosca by providing various tools, parts, and help.

Finally, I want to thank the most important people in my life who are my parents, for raising me and my brothers to be independent human beings and always supporting us on our way. I am very grateful to Olivia for encouraging and motivating me and giving me a home away from home. 


\section{Contents}

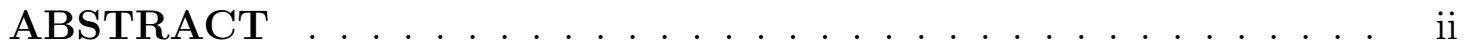

ACKNOWLEDGMENTS .................. iii

Contents ....................... . . iv

List of Tables ........................... . vi

List of Figures . . . . . . . . . . . . . . . . . . . vii

Chapter

1 Introduction . . . . . . . . . . . . . . . . . . . 1

1.1 Introductory Information . . . . . . . . . . . . . . . 1

1.2 Motivation ..................... . . 3

1.3 Theoretical Background ............... 5

1.3.1 Emulsions .................. . . 5

1.3.2 Magnetic Nanoparticles ............. 8

1.3.3 Concrete.................. 10

1.3.4 Self-healing ................ 13

1.3.5 Corrosion Inhibition with Calcium Nitrite . . . . . . . . 14

List of References . . . . . . . . . . . . . . . . . . 15

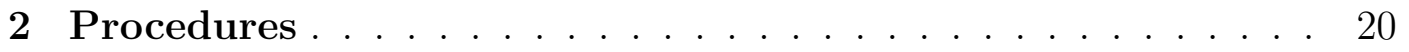

2.1 Materials . . . . . . . . . . . . . . . . 20

2.1.1 Equipment .................. . . 20

2.1.2 Chemicals ................... . . 21 


\section{Page}

2.2 Experimental procedures . . . . . . . . . . . . . . . . 23

2.2.1 Production of Emulsion . . . . . . . . . . . . . . . . . 23

2.2.2 Encapsulation of Emulsion Droplets . . . . . . . . . . 24

2.2 .3 Analysis . . . . . . . . . . . . . . . . . 25

List of References . . . . . . . . . . . . . . . . . 26

3 Results and Discussion $\ldots \ldots \ldots \ldots \ldots \ldots \ldots$

3.1 Setting up of a new equipment $\ldots \ldots \ldots \ldots \ldots$

3.2 Results of Experiments using Hydrophilic Nanoparticles . . . . . 29

3.3 Results of Experiments using Hydrophobic Nanoparticles . . . . 30

3.4 Introduction of Calcium Nitrite into the system $\ldots \ldots \ldots$. . . 34

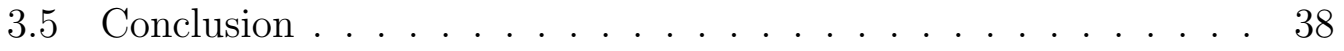

List of References . . . . . . . . . . . . . . . . . . . . 38

4 Future Work . . . . . . . . . . . . . . . . . . . 39

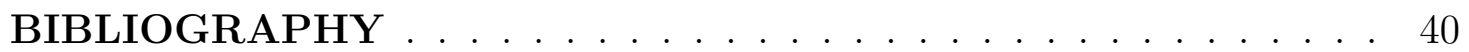




\section{List of Tables}

Table

Page

1 Composition of the oil and water phases for the production of a water-in-toluene emulsion and following encapsulation . . . . . 23

2 Composition of the oil and water phases for the production of a water-in-hexadecane emulsion and following encapsulation . . . 24

3 Different compositions of oil and water phase in experiments to overcome emulsification problems with calcium nitrite (CNI). Adding of hydrophilic particles (EMG700), citric acid (CA), and carbon black particles $(\mathrm{CB}) \ldots \ldots . \ldots . . . . . .36$ 


\section{List of Figures}

Figure

Page

1 Illustration of the position of microcapsules in the concrete matrix (light gray). Random placement (upper) and directed placement (bottom) on the reinforcement bars (dark gray) . . . . . .

2 (Upper) Position of a particle at the oil-water interface for contact angle $\Theta<90^{\circ}$ (left), $\Theta=90^{\circ}$ (center) and $\Theta>90^{\circ}$ (right). (Bottom) Corresponding stabilization of droplets or emulsions. $[17] \ldots \ldots \ldots \ldots \ldots \ldots$

3 Illustration of the polymerization step to form polyurea capsules. Yellow: oil phase, blue: water phase, red: monomer and polymer, black: iron oxide particle . . . . . . . . . . . 25

4 Photograph of the set-up of the Model A air stirrer in the air hood of the laboratory, Crawford Hall, Rm. 109 . . . . . . . . . 28

5 Photograph of result after stirring of $0.30 \mathrm{wt}-\%$ EMG700 suspended in aqueous phase (bottom) with toluene (upper) with magnetic field from a rod magnet (left) . . . . . . . . . .

6 Optical micrograph of a w/o-emulsion with toluene, 0.10 wt- $\%$ EMG900 and 2 vol-\% water . . . . . . . . . . . . 30

$7 \quad$ Optical micrograph of w/o-emulsion with 0.02 wt-\% EMG900 in hexadecane and 2 vol- $\%$ of water . . . . . . . . . . 30

8 Optical micrographs of 5 vol- $\%$ water in hexadecane emulsion with 0.10 wt-\% EMG900 directly after formation (a), after 24 hours (b), after four days (c) and after seven days (d) . . . . .

9 Photograph of a vial containing capsules produced from an EMG900-stabilized emulsion in hexadecane under influence of the magnetic field of a rod magnet . . . . . . . . . . . . . . .

10 Optical micrograph of capsules in a sample attracted to a magnetic field made from $0.10 \mathrm{wt}-\%$ EMG900 in hexadecane suspension with 5 vol- $\%$ water . . . . . . . . . . . . . . . 
11 Cryogenic SEM image of a capsule produced in water in hexadecane emulsion using with 0.10 wt-\% EMG900 nanoparticles and three hours reaction time . . . . . . . . . . . 33

12 SEM image of a dried capsule produced from water in hexadecane emulsion using 0.10wt-\% EMG900 nanoparticles and three hours reaction time . . . . . . . . . . . . 33

13 EDS mapping image of the $K \alpha$-signal of iron (left) and carbon (right) of a dried polyurea capsule . . . . . . . . . . . . 34

14 Optical micrograph of an emulsion with $1.04 \mathrm{M}$ calcium nitrite in water and $0.10 \mathrm{wt}-\%$ EMG900 in hexadecane. Lower right half and small droplets are water . . . . . . . . . . . . 35

15 Optical micrographs of capsules in mixtures of water containing $0.1 \mathrm{M}$ calcium nitrite and $0.005 \mathrm{M}$ citric acid in hexadecane with 0.10 wt-\% EMG900 with different volume ratios of the dispersed phase and reaction time. Left: 2 vol- $\%, 60 \mathrm{~min}$ and right: 5 vol$\%, 180 \min \ldots \ldots \ldots . \ldots . \ldots . \ldots 36$ 


\section{CHAPTER 1}

\section{Introduction}

\subsection{Introductory Information}

Concrete buildings are built all around the world due to the well-known properties that the material has and the comparatively easy way to use it in construction industry. It is especially used for its high compressive strength [1]. Since concrete is prone to failure under tension it is usually equipped with steel reinforcement bars to improve the properties [2]. Structures made of concrete are omnipresent in industrialized countries, if it is pavement, bridges or buildings such as skyscrapers or sports stadiums. Because of different external influences these structures only have a limited lifespan. Examples for these impacts are the weather and cyclic mechanical loadings due to the specific use of the structure namely in bridges. These loads can cause small cracks in the material's surface, which can lead to an ingress of water. In combination with changing seasons the so-called freeze-thawcycle if the temperature drops below $0^{\circ} \mathrm{C}$. Another critical effect is the possible corrosion of the reinforcement bars. This has two main consequences: Firstly, the steel structure is weakened so that the tensile strength of the compound material decreases. Secondly, the volume of oxidized iron is increased in comparison to that of metallic iron. The ratio between these is expressed by the "rust expansion coefficient" [3] whose values are between 2.2 and 6.4 [4]. This expansion puts additional pressure on the concrete matrix resulting in further damage. Thus, improved concrete-based building materials could have a big impact as construction sites that are working on the reparation of damaged structures are permanently present in everyday life. Furthermore, if the damage exceeds a certain limit the

building poses a safety risk and has to be completely replaced. Since all these activities cost a lot of money for constant evaluation and repair increased lifetime 
of structures would mean a positive economical outcome for both private industry and public budgets.

In recent years nano-technology has caught scientific and public interest. In the scientific community especially the opportunities given by different properties based on the material's size are of high interest. It opens chances to increase energy efficiency and save resources [5]. The related risks are researched but seem to draw more attention and discussion in the public and media since the long-term influences to the environment and the human body are not completely known. The lack of detailed knowledge about new technology is likely to promote fear in the population. This missing information can be ascribed to the fact that intense research has not been finished yet. 


\subsection{Motivation}

This thesis has been prepared as part of the consecutive project to develop self-healing concrete that has resulted in several theses before $[6,7,8]$. The overall idea is to create a concrete material that is able to repair small damages like microcracks by itself. This has the purpose to extend the service life of concrete structures such as bridges. A longer service life would in turn reduce the need of physical resources to rebuilt or repair these structures. The continuous evaluation of the deterioration of infrastructure but also the repair work is labor intensive so that money would be saved for public and private budgets [9].

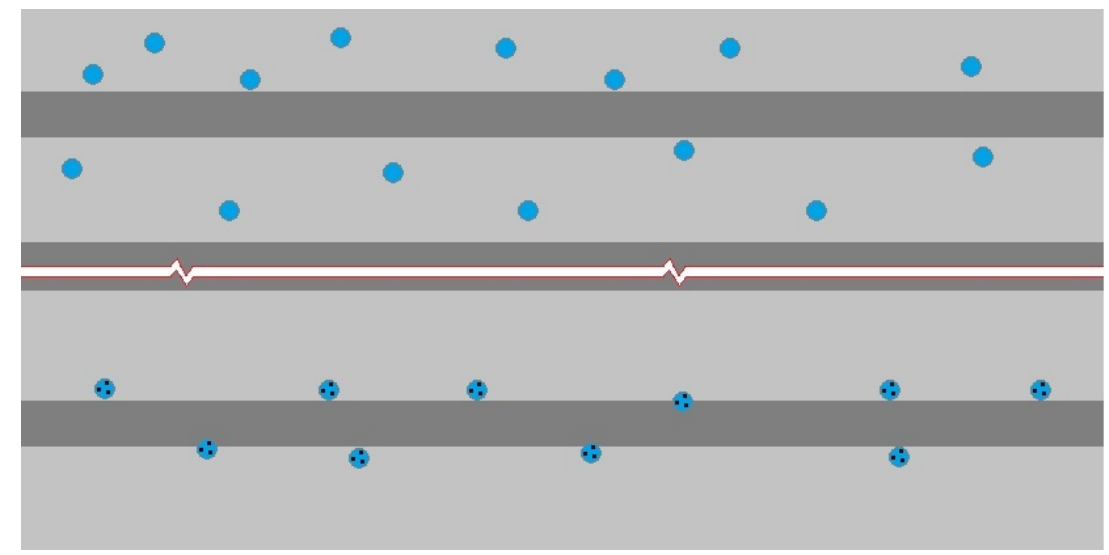

Figure 1. Illustration of the position of microcapsules in the concrete matrix (light gray). Random placement (upper) and directed placement (bottom) on the reinforcement bars (dark gray)

The specific aim of this work is to show a way to produce polymer capsules that are magnetically susceptible. These capsules are thought to contain both a healing agent as well as a corrosion-inhibiting chemical. In the long-term the capsules would be embedded in concrete. The healing agent and the corrosion inhibitor are introduced to reduce corrosion of the reinforcement bars of steel reinforced concrete resulting from water that intrudes into cracks in the concrete matrix. The idea of magnetization is followed in order to open the possibility of specifically placing the capsules onto the reinforcement bars by induced magnetic attraction. This 
arrangement is depicted in figure 1. In the upper part the already implemented way is shown in which the capsules are randomly embedded in the concrete matrix. In contrast to that, the capsules with introduced magnetic nanoparticles (black) are specifically placed on the dark gray reinforcement bars in the bottom part of the image. It will not be part of this work to find a way how this placement can be achieved but it is referred to future work although suggestions will be presented how the author assumes that the task can be achieved. 


\subsection{Theoretical Background}

In this section the essential background related to the problem will be presented. Included are the scientific fields that are important in the production of the capsules in general as well as their magnetization, and also the intended application.

\subsubsection{Emulsions}

An emulsion is a system of at least two immiscible liquid phases in which one is dispersed in the other [10]. The dispersed phase is present in droplets while the other phase is called the continuous phase. The droplets can have a diameter between $10 \mathrm{~m}$ and $50 \mathrm{~mm}$ [11]. Emulsions can be divided into two groups. The first type consists of an aqueous solution as the continuous phase with oil droplets and is called an oil-in-water emulsion $(\mathrm{O} / \mathrm{W})$ whereas in the second type the continuous phase is an organic liquid and water is the dispersed phase. This is called a waterin-oil emulsion (W/O). It is also possible to classify emulsions based on the size of the droplets. If the droplet diameter is in the range of $0.2-50 \mathrm{~mm}$ it is called a macroemulsion. In case the droplets are smaller $(10-200 \mathrm{~m})$, one speaks of a microemulsion [11]. Milk is a common emulsion where oil-droplets are dispersed in water. Emulsions are not limited to two phases but can consist of several phases to form multiple emulsions such as $\mathrm{O} / \mathrm{W} / \mathrm{O}$-emulsions [12].

The stability of emulsions is dependent of different effects. Emulsions can be stabilized with four mechanisms: electrostatically, sterically, with particles or by surface-active molecules (surfactants) [10]. These are molecules, which partly have both hydrophilic and hydrophobic properties. Typically they have a hydrophilic

- Greek for "water loving" - head and a hydrophobic tail that often consists of a carbon chain. The hydrophilicity of the head can result from a number of different atom groups, which at the same time are characteristic to classify surfactants into 
groups. There are ionic and non-ionic surfactants. Ionic types can be subdivided into cationic and anionic depending on the charge. To evaluate what kind of emulsion a surfactant will stabilize there are two theoretical approaches. Firstly the Bancroft's rule says that the phase in which the emulsifier is more soluble becomes the continuous phase. Secondly the Oriented Wedge Theory predicts that the part of the molecule with the greater cross section will be in the dispersion medium [10]. It is possible that an emulsion changes from an o/w-type to w/oemulsion. This process is called phased inversion since the "outer" and "inner" phase change to the respective opposite.

To determine the type of an emulsion a number of test can be done. The dilution test is done by adding one of the constituents of the mixture to the emulsion. For example if water is added and a droplet is recognizable then the emulsion is of the w/o type since water is immiscible in oil. Another possibility to ascertain what constitutes the continuous phase is checking the electrical conductivity. Water is usually much more conductive than oil. There are more tests available, which are not described here.

Emulsification requires a more or less vigorous stirring to form the droplets. During that process the stabilizers, which have been dissolved or suspended in one of the phases before, move to the newly generated interface and stay there to form stable droplets. The size of the emulsion droplets can be controlled by the intensity of stirring. The more energy is introduced to the system the smaller the emulsion droplets will be.

\section{Pickering Emulsions}

In 1903 Ramsden found out that emulsions can be stabilized by fine particles [13] but Pickering's publication in 1907 [14] resulted that this type of emulsion is commonly called "Pickering emulsion". Although Pickering reported an 
improved stability of particle stabilized emulsions compared to surfactant-based ones the former type of emulsions was ignored for a long time [1]. The stabilization of emulsions with particles requires the partial wettability of the particles by both oil and water phase. That is an issue of interfacial energies of the three interfaces solid-water, solid-oil, and oil-water expressed by the respective $\gamma[1]$. A critical parameter to describe the wettability is the contact angle $\Theta$ between the particle and the aqueous phase $[15,16]$. For hydrophilic particles the contact angle is $\Theta<90^{\circ}$ and for hydrophobic ones it accordingly is greater that $90^{\circ}$. This results in hydrophilic particles residing with a larger fraction in the water phase and vice versa as illustrated in figure 2 [17].

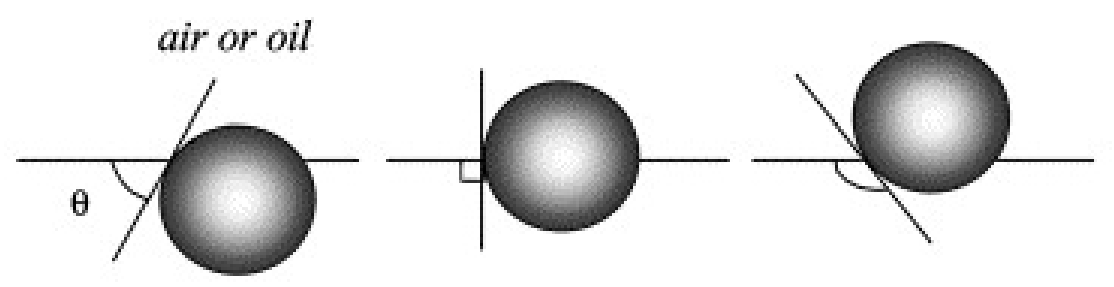

water
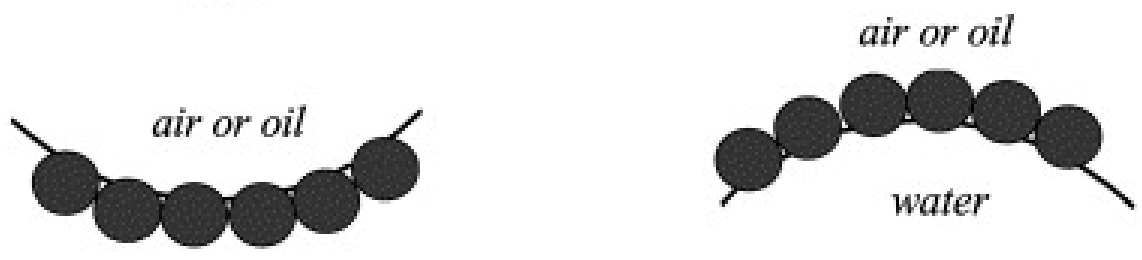

water

Figure 2. (Upper) Position of a particle at the oil-water interface for contact angle $\Theta<90^{\circ}$ (left), $\Theta=90^{\circ}$ (center) and $\Theta>90^{\circ}$ (right). (Bottom) Corresponding stabilization of droplets or emulsions. [17]

The wettability can be changed with several ways such as adjusting pH $[18,19]$, in situ modification with surfactants or surface modification by chemical reaction [20]. The energy E that holds the particles at the interface is expressed by

$$
E=\pi r^{2} \gamma_{o w}(1 \pm \cos \Theta)^{2}
$$


with the particle radius $\mathrm{r}$, the surface tension between oil and water phase $\gamma_{\text {ow }}$ and the contact angle $\Theta[21]$. The sign in the brackets determines if the particle for removal of the particle into the oil phase $(+)$ or water phase $(-)$ [15]. The maximum energy is at a contact angle of $90^{\circ}$ and can reach values of $10^{7} k_{B} T$ for a micrometer sized particle and a surface tension of $50 \mathrm{mN} / \mathrm{m}$ [16]. This means that these particles are more or less irreversible adsorbed to the interface, which results in an enormous stability and high resistance to coalescence [1]. Depending on the system emulsions can be formed with a surface coverage of the droplets of only $5 \%[19]$.

\subsubsection{Magnetic Nanoparticles}

Nanotechnology is the use of materials with nanoscale dimensions in the range of 1-100 nm [22]. The concept of nanotechnology was first proposed by Richard Feynman in 1959 [23] and has since developed in various directions. Structures can be nanosized in one (thin films), two (nanowires), or three (particles) dimensions, respectively [23]. The properties of nanosized materials vary a lot from the bulk phase, which opens up a wide range of new applications in multiple disciplines of science and industry. Nanoscale devices can be superior to conventional materials by a 100 to 1000 fold [24]. Because on these characteristics, nanotechnology is seen as a key technology for the future and as such of very high interest for scientists and governments around the world, which leads to national research initiatives [23]. "Thousands of new patents related to [the field are] announced each year" [22] and it is believed that a new generation of consumer products will be developed based on nanomaterials [23]. Although in science the new possibilities are esteemed there is a certain fear in the public that nanosized particles could enter the human body or accumulate in the environment. Several studies regarding these apprehensions have come do different conclusions [22]. 
A well known example of nanosized material are magnetic nanoparticles, which have been found application in many different fields that include cell labeling, tissue repair, magnetic seals, ferrofluids, and medical use such as hyperthermia or magnetic resonance imaging $[25,26]$. Depending on the application a special property of the particles is taken advantage of. Magnetic nanoparticles usually rely on iron oxides $(\mathrm{FeO})$ existing in nature in multiple forms of which magnetite $\left(\mathrm{Fe}_{3} \mathrm{O}_{4}\right)$, maghemite $\left(\gamma-\mathrm{Fe}_{2} \mathrm{O}_{3}\right)$, and hematite $\left(\alpha-\mathrm{Fe}_{2} \mathrm{O}_{3}\right)$ are most common [26]. Magnetite shows the strongest magnetism but is superparamagnetic below $15-20 \mathrm{~nm}$, meaning that no permanent magnetization is present when there is no magnetic field applied $[19,25,26]$. Iron oxide particles have a large surface area to volume ratio due to their small size and are hydrophobic in their natural condition, which leads to agglomeration and clusters of 50-100 $\mathrm{nm}[19,25]$. To avoid the formation of clusters or to dissolve the particles in aqueous solution the surface is usually coated with surfactants [25] or organic acids for instance oleic acid. When dissolved in water the contact angle (see section 1.3.1) can be manipulated by changing the $\mathrm{pH}$ of the solution, which leads to a protonation or deprotonation of the carboxylic acid group [19]. Besides the hydrophilicity also the chemical stability and functionality of the particles can be tuned by encapsulating the nanoparticles with organic polymers [26]. The size of iron oxide nanoparticles depends on the production process and ranges from 4-200 nm [25]. The most common method to form nanoparticles is via co-precipitation of $\mathrm{Fe}^{2+}$ and $\mathrm{Fe}^{3+}$ aqueous salt solutions [26]. The size and shape of such particles can be controlled by the variation of the used salts, ion ratio, $\mathrm{pH}$ and ionic strength of the media [25]. The nanoparticles can be formed directly in the water phase [27] or with a route forming a w/o-microemulsion where the precipitation takes place within the vesicles [25, 28]. Teja and Koh [26] give examples for a whole list of various methods to form iron oxide nanoparticles us- 
ing gas phase (chemical vapor deposition), before mentioned co-precipitation in liquid phase but also sol-gel methods, and high pressure hydrothermal methods. Depending on the procedure the FeO-particles can be either single precipitates or embedded in beads if needed for further application [29].

\subsubsection{Concrete}

Concrete is a building material that is used all over the world because of its easy workability. It is an old material and has been used by the Romans who already knew the "excellent resistance [of concrete] to water" [30]. Until today buildings such as aqueducts survived and can be found. A big advantage of concrete is that it can be formed in any desired shape using molds. That is why there is a variety of applications where concrete is used which include but are not restricted to infrastructure like roads, and bridges, buildings, water treatment plants, and even boats. It is a comparatively cheap material and is suitable in many locations because the basic materials are available almost all over the world. The main constituents are Portland cement, water, aggregates (fine and coarse), air, and admixtures [2]. There is a concrete paste formed from water and Portland cement and water in which the aggregates are distributed. The mixture is called mortar when there are no coarse aggregates added [30].

Portland cement is the main constituent of the cement paste and is made from limestone and clay in a heating process $\left(900-1000^{\circ} \mathrm{C}[30]\right)$. Afterwards the product that is called clinker, is ground to a powder form [2]. It consists of four different components, which are the reaction products of the sintering process. The main ingredients of cement are Tricalcium silicate, $C_{3} S$, Dicalcium silicate, $C_{2} S$, Tricalcium aluminate, $C_{3} A$, and Tetracalcium aluminoferrate, $C_{4} A F .{ }^{1}$ Anhydrous cement does not bind sand or gravel. This property is only reached after being

\footnotetext{
${ }^{1}$ The letters are not representing chemical elements but are abbreviations commonly used in cement chemistry [30].
} 
mixed with water in a chemical process, called hydration of cement, between 20 and $40^{\circ} \mathrm{C}$ [31]. The amount of water that is added to the mixture is introduced to the water-to-cement ratio, which is a key parameter in comparing concrete mixtures $[2,30]$. Water is consumed in order to form a variety of hydrates, forming a gel as the binding component in concrete. The most important is Calcium Silicate Hydrate (C-S-H). The developed hydroxyl ions are responsible for the high $\mathrm{pH}-$ value of concrete.

In the mixing process of concrete air bubbles are formed within the matrix. Besides the main constituents, admixtures are added to the mixture. These admixtures serve specific desires to manipulate the properties of the readily concrete. Accelerating admixtures reduce the setting time, air entraining admixtures control the size of air bubbles to about $1 \mathrm{~mm}$, which increases the frost resistance by "increas[ing] the resistance [...] to disintegration" [2]. Water reducing admixtures and silica-fume admixtures increase the strength of the material [2].

The strength of concrete is usually looked at by dividing it into compressive strength and tensile flexural strength, respectively. Concrete materials are typically divided in three categories by their respective compressive strength. These are low strength with values up to $20 \mathrm{MPa}$ (3000 psi), moderate strength (20-40 MPa/3000-6000 psi) and high strength reaching values up to $130 \mathrm{MPa}$ (20,000 psi) [30]. As mentioned above admixtures have to be introduced to the mixture. The good compressive strength is one of the reasons for the success of concrete as a building material. As opposed to this the tensile strength only reaches approximately 10 to 15 per cent of the compressive strength $[2,30]$. The "rapid propagation of microcracks under applied stress [...] is responsible for the low tensile strength of [concrete]" [30]. This lack of tensile strength was already known in 1801 by F. Coignet [2]. In response to that property concrete has to be 
reinforced with metal bars that also is a long-known technique. It increases the properties of the compound material a lot while only contributing a little to the overall construction cost [32].

Concrete structures are facing several mechanisms of deterioration. Among others, these include freeze-thaw cycles and corrosion of the reinforcement bars. Small cracks occur naturally in concrete because of the initial shrinking during the setting process of a freshly made structure. Water, which has penetrated into these microcracks, expands when it freezes at temperatures below $0^{\circ} \mathrm{C}$ and exerts stresses to the surrounding material. This leads to a propagation of the crack into the material. If the cracks reach the steel reinforcement bars and water is present, metal corrosion occurs. This has multiple negative influences on the compound material. Firstly, the corrosion products take up more volume than the metal [33, 34], which is expressed by the rust expansion coefficient [3]. Its value is between 2.2 and 6.4 depending on the corrosion product $[4,30]$. The increased volume puts an internal pressure on the concrete matrix surrounding the rebar and leads to cracks or spalling. It was found that "the amount of iron oxide generated during the corrosion of $10-50 \mathrm{~mm}$ of metal [...] is enough to crack a concrete cover of $2-3 \mathrm{~cm} "[35,36]$. Nevertheless, not all of the corrosion products lead to pressure because they migrate through pores [33]. Secondly, the cross area of the reinforcement bars is reduced which decreases the maximum stress the rebar can withstand. However, more important is the fact that the bond strength between the metal bar and the concrete matrix is weakened [33]. In order to prevent or reduce the corrosion, inhibitors can be added which "are usually organic compounds that can migrate through the concrete, forming a protective film around the reinforcing bars" [2]. The presence of salt generally worsens corrosion [33].

A variety of inspection and maintenance techniques are available in order to 
encounter the constant deterioration of concrete structures. Corrosion of steel reinforcement bars is mainly based on electrochemical procedures [35]. Inspection as well as maintenance are labor intensive and hence can make a far greater contribution to the total lifetime cost of a structure than the initial construction cost [37]. There have been different materials developed that can be used as repair materials for Portland cement. Morgan [38] names a "range from polymer modifiers [...] (styrene butadiene) to pure polymers like epoxy resins, polyesters and some polyurethane based systems." Other materials that are not based on Portland cement have also found application. These materials can have disadvantages such as different thermal expansion coefficient than concrete or can pose hazards [39].

\subsubsection{Self-healing}

Natural materials often have the ability to detect and automatically repair damages. These self-healing mechanisms are present on different levels and take place in soft tissues, bones, and skin of plants and animals, respectively [40, 41, 42]. Even though these healing processes are very complex, there have been attempts to adapt them into technical systems [41]. The transfer of natural mechanisms into technical application is called biomimetics [40].

Self-healing mechanisms have been developed for different types of materials and are divided into two classes: intrinsic and extrinsic systems [43, 44]. "Intrinsic systems recover through an inherent property of the material" [43] and can heal damage repeatedly whereas "extrinsic systems rely on incorporating secondary materials" [43] and thus are usually irreversible.

The early developments of artificial repair mechanisms in relied on outside influence like heating to start the process before White et al. [45] reported a completely autonomous healing process in a polymeric material. They inserted a healing agent in microcapsules and added a catalyst to the matrix. A variety of other 
examples in polymers has been published since [46].

Since the effort for maintenance and repair of concrete architecture can be very costly, especially for large-scale structures where the capital requirements can even be prohibitive [42], it is desirable to have building materials with selfrepair abilities. The natural self-healing capacity of concrete is long known in water retaining structures [42]. Different approaches to establish artificial selfrepair mechanisms have been reported. Song et al. [44] apply a protective polymer coating on the concrete surface with aforementioned capsule embedding system using sunlight as the catalyst. Also several techniques of implying self-healing ability in the cementitious material itself are known [42]. They use healing agents that are stored in embedded hollow fibers or microcapsules, expansive agents, shape memory materials, and even bacteria [42]. The bacteria are special strains whose metabolic products lead to the precipitation of calcium carbonate [39, 47]. The embedding of microcapsules, successfully demonstrated by Pelletier [6], will be adopted in the present work.

\subsubsection{Corrosion Inhibition with Calcium Nitrite}

In regular concrete the steel rebars are passivated because of the high $\mathrm{pH}$ value due to the presence of calcium hydroxide in the pores of the cement matrix, which leads to a thin oxide layer on the steel surface $[48,49,50]$. Corrosion of the reinforcement bars is only initiated if the protective layer on the surface is damaged which can be caused by a decreased $\mathrm{pH}$ or a high local concentration of chlorides around the rebars [48, 49].

There is the desire to prevent the corrosion of the reinforcement to avoid the negative impacts on the entire structure as presented in sections 1.1 and 1.3.3. First of all the corrosion initiation time can be increased by improving the quality of the

used concrete [49]. Besides this basic approach there are several systems to protect 
the steel. Sideris and Savva [49] name among others corrosion inhibitors, epoxy coated steel, and surface impregnation of concrete to be marketed with corrosion inhibitors being very popular. A corrosion inhibitor ideally has no adverse effect on the concrete matrix [49]. The most extensively tested substance is Calcium Nitrite (CNI) [51] which is commercially available in aqueous solution of $30 \mathrm{wt}-\%$ e.g. Rheocrete ${ }^{\circledR}$. A reason for the popularity of this corrosion inhibitor is its simple and relatively economical application because the aqueous solution can be mixed directly into the fluid concrete while processing. It can even be introduced to the system when corrosion has already occured, penetrating into the concrete and repassivating the steel under specific circumstances $[48,51]$. Calcium nitrite is an anodic inhibitor that strengthens the passive film on the steel as expressed in equation 2 [49].

$$
\mathrm{Fe}^{+}+2 \mathrm{OH}^{-}+2 \mathrm{NO}_{2}^{-} \rightarrow \gamma-\mathrm{Fe}_{2} \mathrm{O}_{3}+2 \mathrm{NO}+\mathrm{H}_{2} \mathrm{O}
$$

The successful suppression of corrosion by nitrite ions in presence of chloride ions depends on the ratio of these two ions $[49,51]$.

\section{List of References}

[1] Y. Chevalier and M.-A. Bolzinger, "Emulsions stabilized with solid nanoparticles: Pickering emulsions," Colloids and Surfaces A: Physicochemical and Engineering Aspects, 2013.

[2] E. G. Nawy, Reinforced concrete: A fundamental approach, 5th ed., ser. Prentice-Hall international series in civil engineering and engineering mechanics. Upper Saddle River and N.J: Pearson Education, 2005.

[3] S. Caré, Q. Nguyen, V. L'Hostis, and Y. Berthaud, "Mechanical properties of the rust layer induced by impressed current method in reinforced mortar," Cement and Concrete Research, vol. 38, no. 8-9, pp. 1079-1091, 2008.

[4] Y. Zhao, H. Ren, H. Dai, and W. Jin, "Composition and expansion coefficient of rust based on x-ray diffraction and thermal analysis," Corrosion Science, vol. 53, no. 5, pp. 1646-1658, 2011. 
[5] T. Burgdorf, R. Packroff, P. Apel, and Meyer-Plath Asmus, "1. bilanz zur gemeinsamen Forschungsstrategie der Ressortforschungseinrichtungen des Bundes "Nanotechnologie - Gesundheits- und Umweltrisiken von Nanomaterialien" (2007 - 2011)," 2013.

[6] M. Pelletier, "Self-healing concrete," Master's thesis, University of Rhode Island, Kingston RI, 2010.

[7] T. Bhattacharyya, "Self healing in concrete materials," Master's thesis, University of Rhode Island, Kingston RI, 2011.

[8] S. K. Reinke, "Polyurea/polyurethane microcapsules based self healing concrete," Master's thesis, University of Rhode Island, Kingston RI, 2012.

[9] H.-W. Song and V. Saraswathy, "Corrosion monitoring of reinforced concrete structures - a review," International Journal of Electrochemical Science, vol. 2, no. 1, 2007.

[10] A. Kwade, "Formulierungstechnik - Emulsionen," 06/21/2012, class presentation.

[11] Z. Király, "Colloid chemistry: Lecture 13: Emulsions," 10/09/2013. [Online]. Available: http://koll1.chem.u-szeged.hu/colloids/staff/zoli/ Pharmacy/Lecture\%2013.pdf

[12] S.-H. Kim and D. A. Weitz, "One-step emulsification of multiple concentric shells with capillary microfluidic devices," Angewandte Chemie, vol. 123, no. 37, pp. 8890-8893, 2011.

[13] W. Ramsden, "Separation of solids in the surface-layers of solutions and 'suspensions' (observations on surface-membranes, bubbles, emulsions, and mechanical coagulation). - preliminary account," Proceedings of the Royal Society of London, vol. 72, no. 477-486, pp. 156-164, 1903.

[14] S. U. Pickering, "Emulsions," Journal of the Chemical Society, Transactions, vol. 91, pp. 2001-2021, 1907.

[15] B. P. Binks and S. O. Lumsdon, "Effects of oil type and aqueous phase composition on oil-water mixtures containing particles of intermediate hydrophobicity," Physical Chemistry Chemical Physics, vol. 2, no. 13, pp. 8622-8631, 2000 .

[16] S. Melle, M. Lask, and G. G. Fuller, "Pickering emulsions with controllable stability," Langmuir, vol. 21, no. 6, pp. 2158-2162, 2005.

[17] B. P. Binks, "Particles as surfactants - similarities and differences," Current Opinion in Colloid \&5 Interface Science, vol. 7, no. 1-2, pp. 21-41, 2002. 
[18] Q. Lan, C. Liu, F. Yang, S. Liu, J. Xu, and D. Sun, "Synthesis of bilayer oleic acid-coated fe3o4 nanoparticles and their application in ph-responsive pickering emulsions," Journal of Colloid and Interface Science, vol. 310, no. 1, pp. 260-269, 2007.

[19] D. R. Ingram, C. Kotsmar, K. Y. Yoon, S. Shao, C. Huh, S. L. Bryant, T. E. Milner, and K. P. Johnston, "Superparamagnetic nanoclusters coated with oleic acid bilayers for stabilization of emulsions of water and oil at low concentration," Journal of Colloid and Interface Science, vol. 351, no. 1, pp. 225-232, 2010.

[20] X. Qiao, J. Zhou, B. P. Binks, X. Gong, and K. Sun, "Magnetorheological behavior of pickering emulsions stabilized by surface-modified fe3o4 nanoparticles," Colloids and Surfaces A: Physicochemical and Engineering Aspects, vol. 412, pp. 20-28, 2012.

[21] B. P. Binks and S. O. Lumsdon, "Influence of particle wettability on the type and stability of surfactant-free emulsions $\dagger, "$ Langmuir, vol. 16, no. 23, pp. 8622-8631, 2000.

[22] M.-F. Chen, Y.-P. Lin, and T.-J. Cheng, "Public attitudes toward nanotechnology applications in taiwan," Technovation, vol. 33, no. 2-3, pp. 88-96, 2013.

[23] K. Miyazaki and N. Islam, "Nanotechnology systems of innovation - an analysis of industry and academia research activities," Technovation, vol. 27, no. 11, pp. 661-675, 2007.

[24] R. Datta and S. S. Jaitawat, "Nanotechnology - the new frontier of medicine," Medical Journal Armed Forces India, vol. 62, no. 3, pp. 263-268, 2006.

[25] A. K. Gupta and M. Gupta, "Synthesis and surface engineering of iron oxide nanoparticles for biomedical applications," Biomaterials, vol. 26, no. 18, pp. 3995-4021, 2005.

[26] A. S. Teja and P.-Y. Koh, "Synthesis, properties, and applications of magnetic iron oxide nanoparticles," Progress in Crystal Growth and Characterization of Materials, vol. 55, no. 1-2, pp. 22-45, 2009.

[27] G. Liu, H. Yang, J. Zhou, S.-J. Law, Q. Jiang, and G. Yang, "Preparation of magnetic microspheres from water-in-oil emulsion stabilized by block copolymer dispersant," Biomacromolecules, vol. 6, no. 3, pp. 1280-1288, 2005.

[28] J. Eastoe and B. Warne, "Nanoparticle and polymer synthesis in microemulsions," Current Opinion in Colloid $\&$ Interface Science, vol. 1, no. 6, pp. 800-805, 1996. 
[29] S. Abramson, W. Safraou, B. Malezieux, V. Dupuis, S. Borensztajn, E. Briot, and A. Bée, "An eco-friendly route to magnetic silica microspheres and nanospheres," Journal of Colloid and Interface Science, vol. 364, no. 2, pp. 324-332, 2011.

[30] P. K. Mehta and P. Monteiro, Concrete: Structure, properties, and methods, 2nd ed., ser. Prentice-Hall international series in civil engineering and engineering mechanics. Englewood Cliffs and N.J: Prentice Hall, 1993.

[31] I. Biczók, Concrete corrosion and concrete protection, 3rd ed. New York: Chemical Pub. Co., 1967.

[32] D. V. Val and M. G. Stewart, "Life-cycle cost analysis of reinforced concrete structures in marine environments," Structural Safety, vol. 25, no. 4, pp. 343$362,2003$.

[33] K. Kiani and H. M. Shodja, "Prediction of the penetrated rust into the microcracks of concrete caused by reinforcement corrosion," Applied Mathematical Modelling, vol. 35, no. 5, pp. 2529-2543, 2011.

[34] J. Cabrera, "Deterioration of concrete due to reinforcement steel corrosion," Cement and Concrete Composites, vol. 18, no. 1, pp. 47-59, 1996.

[35] J. González, C. Andrade, C. Alonso, and S. Feliu, "Comparison of rates of general corrosion and maximum pitting penetration on concrete embedded steel reinforcement," Cement and Concrete Research, vol. 25, no. 2, pp. 257264, 1995.

[36] C. Andrade, C. Alonso, and F. J. Molina, "Cover cracking as a function of bar corrosion: Part i-experimental test," Materials and Structures, vol. 26, no. 8, pp. 453-464, 1993.

[37] A. C. Estes and D. M. Frangopol, "Minimum expected cost-oriented optimal maintenance planning for deteriorating structures: application to concrete bridge decks," Reliability Engineering 85 System Safety, vol. 73, no. 3, pp. 281-291, 2001.

[38] D. Morgan, "Compatibility of concrete repair materials and systems," Construction and Building Materials, vol. 10, no. 1, pp. 57-67, 1996.

[39] K. van Tittelboom, N. d. Belie, W. d. Muynck, and W. Verstraete, "Use of bacteria to repair cracks in concrete," Cement and Concrete Research, vol. 40, no. 1, pp. 157-166, 2010.

[40] B. Bhushan, "Biomimetics: lessons from nature-an overview," Philosophical Transactions of the Royal Society A: Mathematical, Physical and Engineering Sciences, vol. 367, no. 1893, pp. 1445-1486, 2009. 
[41] M. Rampf, O. Speck, T. Speck, and R. H. Luchsinger, "Self-repairing membranes for inflatable structures inspired by a rapid wound sealing process of climbing plants," Journal of Bionic Engineering, vol. 8, no. 3, pp. 242-250, 2011.

[42] M. Wu, B. Johannesson, and M. Geiker, "A review: Self-healing in cementitious materials and engineered cementitious composite as a self-healing material," Construction and Building Materials, vol. 28, no. 1, pp. 571-583, 2012.

[43] S. Neuser, V. Michaud, and S. R. White, "Improving solvent-based self-healing materials through shape memory alloys," Polymer, vol. 53, no. 2, pp. 370-378, 2012.

[44] Y.-K. Song, Y.-H. Jo, Y.-J. Lim, S.-Y. Cho, H.-C. Yu, B.-C. Ryu, S.-I. Lee, and C.-M. Chung, "Sunlight-induced self-healing of a microcapsule-type protective coating," ACS Applied Materials 6 Interfaces, vol. 5, no. 4, pp. 1378$1384,2013$.

[45] S. R. White, N. R. Sottos, P. H. Geubelle, J. S. Moore, M. R. Kessler, S. R. Sriram, E. N. Brown, and S. Viswanathan, "Autonomic healing of polymer composites," Nature, vol. 409, no. 6822, pp. 794-797, 2001.

[46] D. Y. Wu, S. Meure, and D. Solomon, "Self-healing polymeric materials: A review of recent developments," Progress in Polymer Science, vol. 33, no. 5, pp. 479-522, 2008.

[47] H. M. Jonkers, A. Thijssen, G. Muyzer, O. Copuroglu, and E. Schlangen, "Application of bacteria as self-healing agent for the development of sustainable concrete," Special Issue: BioGeoCivil Engineering, vol. 36, no. 2, pp. 230-235, 2010.

[48] V. T. Ngala, C. L. Page, and M. M. Page, "Corrosion inhibitor systems for remedial treatment of reinforced concrete. part 1: calcium nitrite," Corrosion Science, vol. 44, no. 9, pp. 2073-2087, 2002.

[49] K. K. Sideris and A. E. Savva, "Durability of mixtures containing calcium nitrite based corrosion inhibitor," Cement and Concrete Research in Greece, vol. 27, no. 2, pp. 277-287, 2005.

[50] N. S. Berke and M. C. Hicks, "Predicting long-term durability of steel reinforced concrete with calcium nitrite corrosion inhibitor," Corrosion Inhibitors, vol. 26, no. 3, pp. 191-198, 2004.

[51] A. Królikowski and J. Kuziak, "Impedance study on calcium nitrite as a penetrating corrosion inhibitor for steel in concrete," ELECTROCHEMICAL IMPEDANCE SPECTROSCOPY, vol. 56, no. 23, pp. 7845-7853, 2011. 


\section{CHAPTER 2}

\section{Procedures}

In this chapter all information about the practical work is presented. The chemicals and equipment are named in the first section. In the second section a detailed description of the methods is given. For some of the utilized equipment a short outline of the function is included.

\subsection{Materials}

In this section all equipment and chemicals, that have been used during the research and experiments including preliminary and side experiments, will be presented.

\subsubsection{Equipment}

Multiple equipment was used throughout the project for different tasks. If no information was available the weight content of nanoparticles of the purchased products were evaluated by evaporating the solvent in a Model 10 Lab Oven from Quincy Lab, Inc., Chicago, IL. The weight of the dry mass was put in relation to the initial weighed in solution. Weighing was always conducted with an analytical balance ACCULAB ALC-80.4 from Sartorius AG, Göttingen, Germany. Nanoparticles have been suspended in both oil and water by ultrasonication in a Bransonic $^{\circledR} 2510$ Ultrasonic cleaner made by Branson Ultrasonics Corp., Danbury, CT. For the emulsification of water in oil two different apparatuses were utilized. For bigger volumes of more than $40 \mathrm{ml}$ a $707 \mathrm{SB}$ explosion resistant blender from Waring Commercial, Torrington, CT, was used while for smaller volumes a Mini Vortexer MV1 from IKA ${ }^{\circledR}$ Works, Inc., Wilmington, NC, had to be applied since the geometry of the blender does not allow to handle such small volumes. 
The polymerization reaction was usually conducted in glass beakers on a stirring hot plate model PC-420D from Corning ${ }^{\circledR}$ Inc., Tewksbury, MA, with a magnetic stirrer. Due to negative interactions between the magnetic nanoparticles and the stirrer bar, an overhead stirrer was purchased and installed as explained in section 3.1. All possibly precarious work was done under an air hood. Glassware and pipettes used during the work were standard laboratory equipment.

\subsubsection{Chemicals}

A number of chemicals has been used in this work. Initial experiments used surfactants poly(ethylene glycol) dioleate from Sigma-Aldrich, Co., St. Louis, MO, and Span ${ }^{\circledR} 85$ also from Sigma-Aldrich. Solvent used was toluene HPLC grade from Fisher Scientific, Fair Lawn, NJ. DI water available in the laboratory was applied. For the polymerization reaction a monomer and a catalyst was needed. Basonat ${ }^{\circledR}$ F 200 WD, BASF SE, Ludwigshafen, Germany, served as the monomer while Dibutyltin dilaurate from Sigma-Aldrich was the catalyst. Corrosion inhibitor Rheocrete ${ }^{\circledR}$ from BASF Corp., Allentown, PA, was introduced in the aqueous core of capsules which contains $30 \mathrm{wt}-\%$ calcium nitrite as the active ingredient. Additionally citric acid (99+\%) from Alfa Aesar, Ward Hill, MA, was used.

Experiments were conducted in order to replace toluene as the solvent. Hexadecane, 99\% from Aldrich Chemical Company, Inc., Milwaukee, WI, n-octane 99+\%, and cyclohexane for HPLC, Acros Organics, NJ was applied.

In the advanced experiments various iron oxide nanoparticles were introduced to the system. From Ferrotec Corporation, Bedford, NH, the types EMG700, EMG605, and EMG900 from the EMG series as well as the EFH1 type were utilized. The water-soluble iron oxides SHP-05, SHP-50, SHA-30 and the organic soluble type SOR-30, all from Ocean NanoTech, LLC, Springdale, AR, were ap- 
plied. Furthermore, PVP Magnetite Nanopowder from nanoComposix, San Diego, CA was employed. All iron oxide nanoparticles were kindly made available by the respective manufacturers.

Fumed silica particles TG-828F from Cabot Corporation, Billerica, MA, were applied in selected tests along with an additional surfactant Aerosol OT from Fisher Chemical, Fair Lawn,NJ. CAB-O-JET ${ }^{\circledR} 300$ from Cabot Corp., Billerica, MA, was used for containing carbon black particles. All used chemicals were used as received. 


\subsection{Experimental procedures}

For producing the samples of emulsions and capsules the techniques and processes described in the following have been applied.

\subsubsection{Production of Emulsion}

The process for the production of emulsions was borrowed from Pelletier [1], who originally adopted the method from Saihi et al. [2]. A water-in-oil emulsion is formed with toluene serving as continuous phase. The originally used surfactants Span ${ }^{\circledR} 85$ and poly(ethylene glycol) dioleate are replaced by hydrophobic iron oxide nanoparticles in order to stabilize a Pickering emulsion. The composition of the phases for emulsification of water in toluene is given in table 1 .

Table 1. Composition of the oil and water phases for the production of a waterin-toluene emulsion and following encapsulation

\begin{tabular}{rll}
\hline \multicolumn{1}{c}{ Phase } & Composition & Amount \\
\hline \multirow{2}{*}{ Continuous } & toluene & $22 \mathrm{ml}$ \\
& EMG900 & $13.4 \mu \mathrm{l}$ or $26.8 \mu \mathrm{l}$ \\
\hline \multirow{2}{*}{ Aliquot } & toluene & $3 \mathrm{ml}$ \\
& Basonat & $20 \mu \mathrm{l}$ per ml water \\
& Dibutyltin dilaurate & $15.6 \mu \mathrm{l}$ per ml water \\
\hline Dispersed & water & $510 \mu \mathrm{l}$ \\
\hline
\end{tabular}

The nanoparticles were initially in suspension and a volume appropriately to the desired mass percentage of the oil phase was added to toluene. To ensure a good suspension in toluene the sample was put in an ultrasonic bath for $30 \mathrm{~min}$. Then, the aqueous phase was added to the oil and emulsified with the vortex mixer on $3000 \mathrm{rpm}$ for two minutes.

For experiments using hexadecane instead of toluene the volume of the oil phase was kept constant. The volume of original nanoparticle suspension had to be adjusted to the different density of the liquid in order to retain the weight percentage of particle in solution. The composition of suspensions and solutions 
for hexadecane-based experiments are given in table 2 The volume of dispersed phase is chosen according to a water-to-oil ratio so that no variation was needed.

Table 2. Composition of the oil and water phases for the production of a waterin-hexadecane emulsion and following encapsulation

\begin{tabular}{rll}
\hline \multicolumn{1}{c}{ Phase } & Composition & Amount \\
\hline \multirow{2}{*}{ Continuous } & hexadecane & $22 \mathrm{ml}$ \\
& EMG900 & $10.4 \mu \mathrm{l}$ or $20.8 \mu \mathrm{l}$ \\
\hline \multirow{2}{*}{ Aliquot } & hexadecane & $3 \mathrm{ml}$ \\
& Basonat & $20 \mu \mathrm{l}$ per ml water \\
& Dibutyltin dilaurate & $15.6 \mu \mathrm{l}$ per ml water \\
\hline Dispersed & water & $510 \mu \mathrm{l}$ \\
\hline
\end{tabular}

Control images of the emulsion were gained with optical microscopy before going on to the next step.

\subsubsection{Encapsulation of Emulsion Droplets}

The encapsulation is reached via interfacial polymerization of the diisocyanate with water to form polyurea. The reaction takes place in two steps. At first an amine is formed which then reacts with an isocyanate to polyurea. An illustration of the desired result is given in figure 3 .

After successful formation of the emulsion, the supernatant suspension phase was replaced with $40 \mathrm{ml}$ of fresh oil for dilution purposes. Monomer and catalyst were added to the aliquot regarding the used volume of water: Per milliliter of water $15.6 \mu \mathrm{l}$ dibutyltin dilaurate and $20 \mu \mathrm{l}$ Basonat was appended as indicated in tables 1 and 2 .

The stirrer preparation procedure was conducted and the emulsion was then transferred to the reaction beaker. After adding the aliquot the stirring process is started and the air pressure on the stirrer is set to 20 psi. The mixture is kept at room temperature. Depending on the experiment 10-20 min after starting the polymerization process the temperature of the hot plate is raised to approximately 


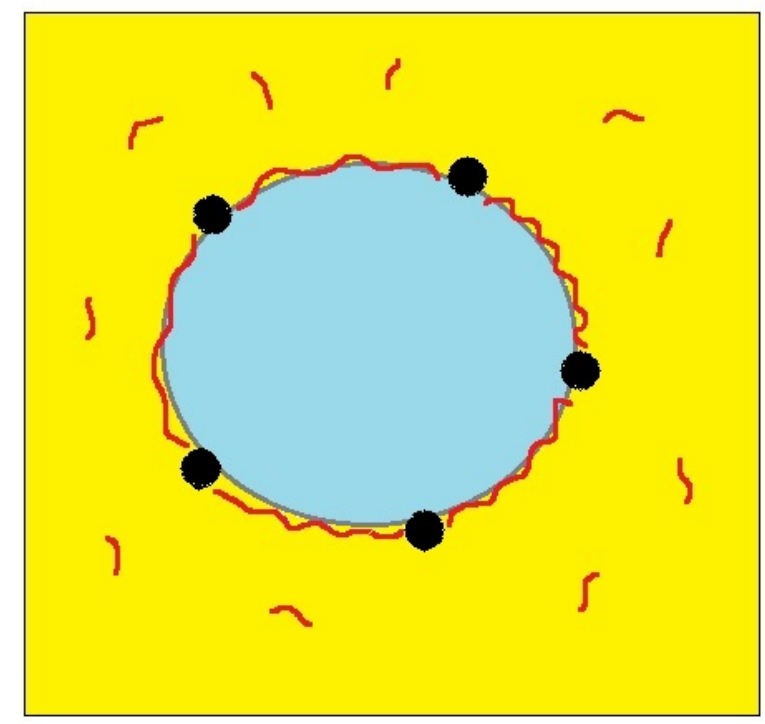

Figure 3. Illustration of the polymerization step to form polyurea capsules. Yellow: oil phase, blue: water phase, red: monomer and polymer, black: iron oxide particle

$125^{\circ} \mathrm{C}$, which corresponds to a solution temperature of about $59^{\circ} \mathrm{C}$. Continuous optical control was done along with adjustment of the air pressure. The total reaction time was three hours. Samples of the capsules were taken for examination with microscopy.

\subsubsection{Analysis}

The emulsions and capsules have been analyzed using both optical and electron microscopes. Optical micrographs were taken using a Nikon DIAPHOT microscope with a Nikon DS-U2 digital camera attached to it. The camera was connected to a computer running Nikon NIS-Elements F 3.0 imaging software. Also a Fisher Scientific MICROMASTER ${ }^{\circledR}$ with a digital camera and Micron(USB2) software has been used. Samples were prepared on regular glass microscope slides, partly between two slides being separated by a cover slip to avoid quick evaporation.

A field emission scanning electron microscope (FESEM) IGMA $^{\mathrm{TM}}$ VP from Zeiss AG, Germany, was utilized. In order to take micrographs of the emulsion phase the cryogenic sample preparation had to be applied. An ALTO 2500 cryo- 
transfer unit from Gatan, Inc., Abingdon, United Kingdom, is available. In cryogenic preparation of a liquid sample a droplet is put on the sample holder, which is then immersed into liquid nitrogen where it freezes almost instantly. This rapid freezing prohibits the growth of ice crystals. The sample is hold under vacuum to prevent melting. The sample holder is then transferred to the preparation chamber where the droplet can be fractured to reveal the inside of the frozen liquid. Before the sample holder is introduced to the microscope chamber a gold and platinum composite is sputtered on the surface of the sample to provide conductivity, which is vital for electron imaging.

The FESEM is equipped with a $50 \mathrm{~mm}^{2}$ detector X-MAX for energy-dispersive X-ray spectroscopy (EDS) from Oxford Instruments, Abingdon, UK. Analyzing

software AZtecEnergy is used with the detector. EDS allows gathering data about the elemental composition of a sample can be.

\section{List of References}

[1] M. Pelletier, "Self-healing concrete," Master's thesis, University of Rhode Island, Kingston RI, 2010.

[2] D. Saihi, I. Vroman, S. Giraud, and S. Bourbigot, "Microencapsulation of ammonium phosphate with a polyurethane shell. part ii. interfacial polymerization technique," Reactive and Functional Polymers, vol. 66, no. 10, pp. 1118-1125, 2006. 


\section{CHAPTER 3}

\section{Results and Discussion}

In this chapter all the findings and results of the conducted experiments will be presented and discussed.

\subsection{Setting up of a new equipment}

In order to successfully produce capsules with magnetic nanoparticles embedded into the polymer wall the magnetic stirrer used in the established process had to be replaced. This had to be done to avoid the magnetic field of the equipment attracting or interfering with the nanoparticles. An overhead stirrer Model A from Arrow Engineering Co., Inc., Hillside, NJ, which is air driven to meet safety requirements with the used chemicals was purchased and installed with standard operating procedures. The set up is shown in figure 4. The stirrer is mounted on a stand, which was available in the lab. An air filter and regulator is installed in the air supply line of the motor. The default stirrer shaft propeller of the equipment was replaced by a Caframo ${ }^{\mathrm{TM}}$ straight blade impeller with a smaller diameter of $31.75 \mathrm{~mm}$ to fit the used glass beakers. A custom made Jacobs chuck to connect the stirrer with the motor was purchased directly from Arrow Engineering. In order to avoid harmful vapors in the air hood a sheet of Polytetrafluoroethylene (commercially known as Teflon $\left.{ }^{\circledR}\right)$ for covering the beaker was purchased and customized to fit the stirrer and beaker. During operation the sheet is additionally fixed by a clamp. The beaker is heated in the course of use by a hot plate Isotemp ${ }^{\mathrm{TM}}$ from Fisher Scientific ${ }^{\mathrm{TM}}$, replacing the previously used magnetic stirring hot plate to avoid any magnetic field. The supply hose was equipped with a three-way valve which allows to purge the air coming from the central supply system, which is humid, before operation to avoid corrosion within the motor. Alternatively com- 
pressed gas like nitrogen or air from a gas bottle can be used to run the stirrer. The equipment has proven functionality and has been successfully used in multiple experiments.

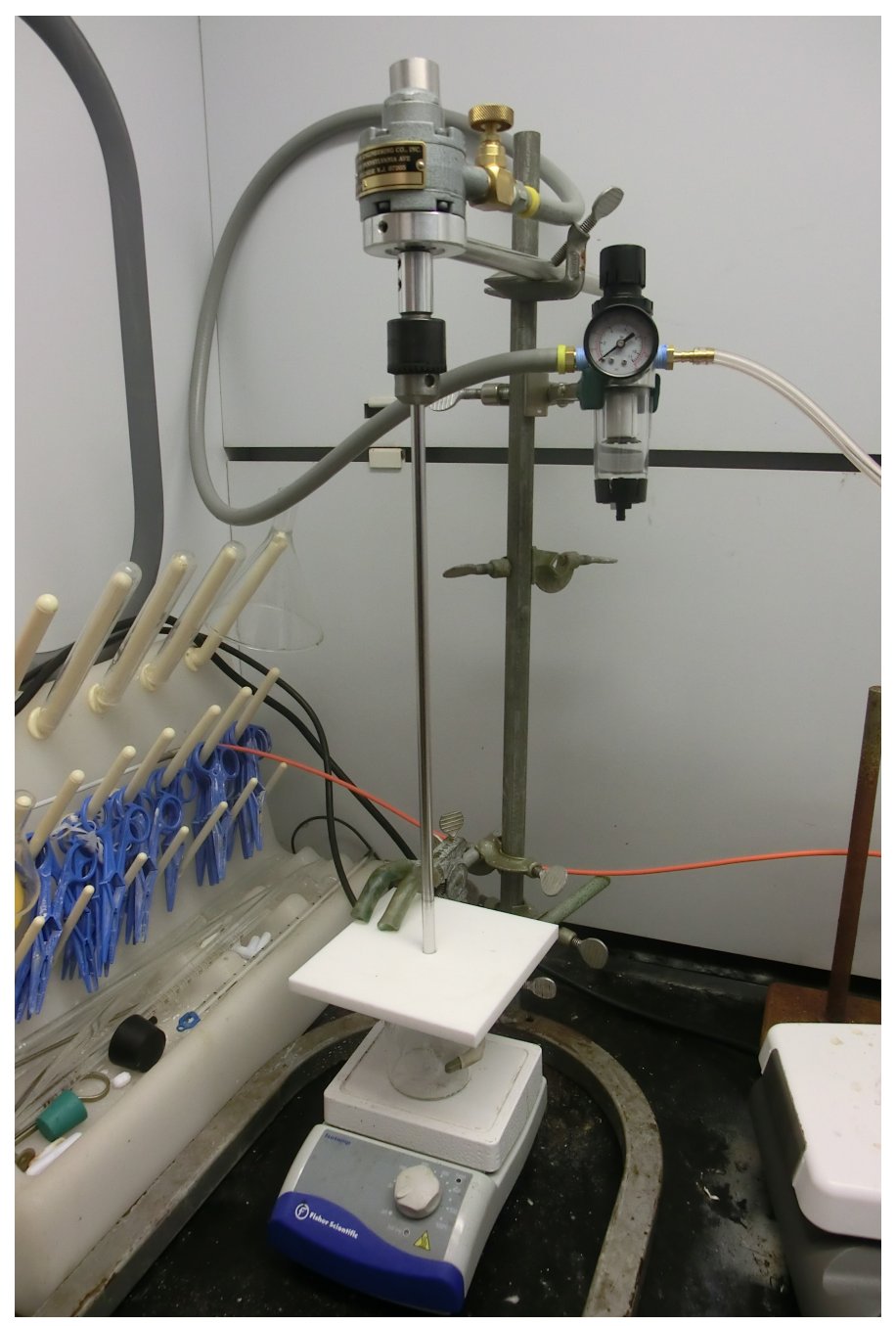

Figure 4. Photograph of the set-up of the Model A air stirrer in the air hood of the laboratory, Crawford Hall, Rm. 109 


\subsection{Results of Experiments using Hydrophilic Nanoparticles}

The initial approach to just include hydrophilic iron oxide nanoparticles in the aqueous phase was realized using different commercially available products. It was seen that a stable emulsion could not be formed. A dispersion of $0.30 \mathrm{wt}-\%$ EMG700 nanoparticles in the water phase lead to a situation as shown in figure 5 even after vigorous stirring of a mixture with toluene.

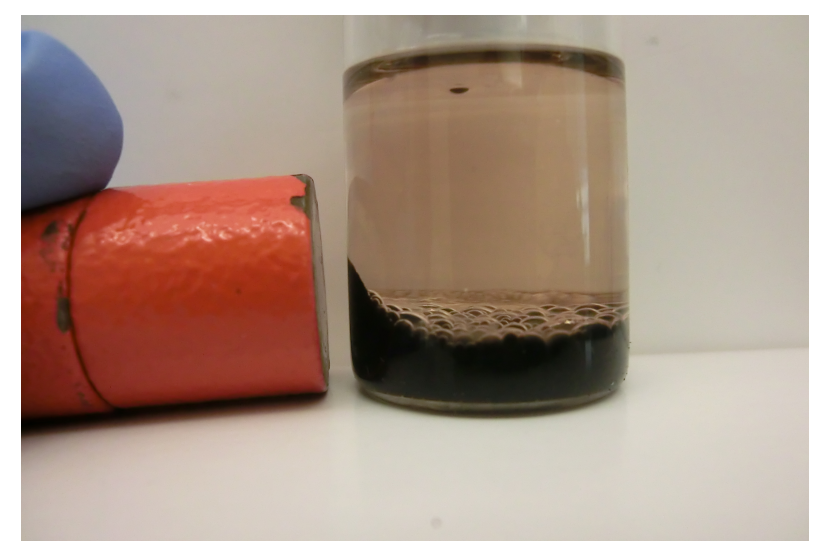

Figure 5. Photograph of result after stirring of $0.30 \mathrm{wt}-\%$ EMG700 suspended in aqueous phase (bottom) with toluene (upper) with magnetic field from a rod magnet (left)

It can be clearly seen that no emulsion has formed but phase separation has occurred with the aqueous phase on the bottom due to its higher density. The water phase is receptive to the magnetic field from the rod magnet, which proves the practicability of that simple test to check magnetic susceptibility. Similar outcome was observed using a series of other hydrophilic particles like SHP-series and PVP-capped nanoparticles. These observations are supported by theoretical considerations because hydrophilic particles are more likely to stabilize an o/wemulsion rather than the desired w/o-type (see section 1.3.1). Based on these results the decision was made to turn to the use of hydrophobic nanoparticles that are suspended in the oil phase. 


\subsection{Results of Experiments using Hydrophobic Nanoparticles}

The used hydrophobic particles of the EMG900 series were successful in stabilizing a w/o-emulsion using both toluene and hexadecane as the oil phase. Optical micrographs of an emulsion of each system are shown in figures 6 and 7 .

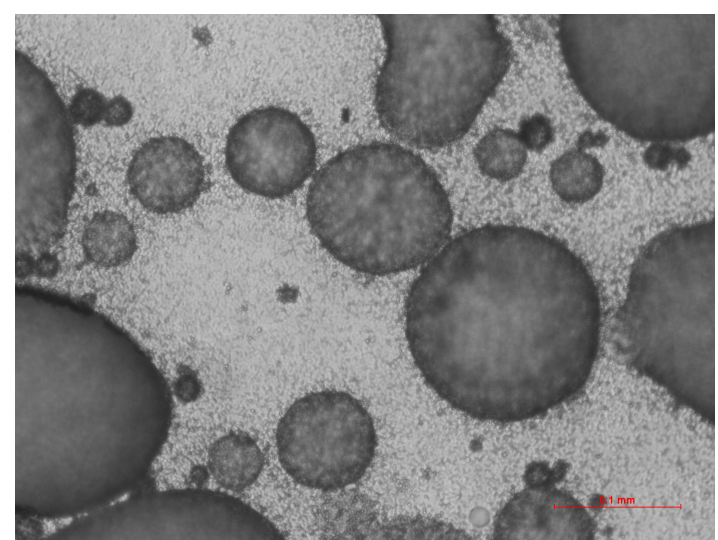

Figure 6. Optical micrograph of a w/o-emulsion with toluene, $0.10 \mathrm{wt}-\%$ EMG900 and 2 vol- $\%$ water

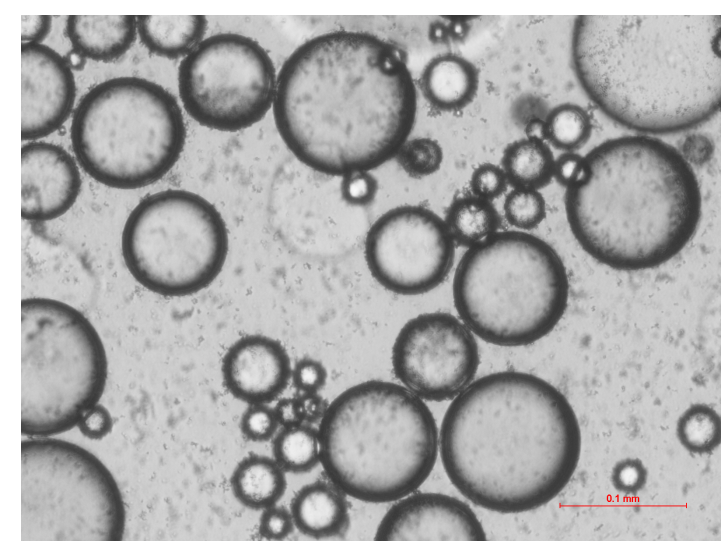

Figure 7. Optical micrograph of w/oemulsion with $0.02 \mathrm{wt}-\%$ EMG900 in hexadecane and 2 vol- $\%$ of water

Both micrographs (figures 6 and 7) are representative for the samples and show a similar size distribution of the formed droplets with a range between 200$100 \mu \mathrm{m}$. The darker appearance of the droplets in figure 6 is due to the higher particle loading caused by a greater concentration in the continuous phase.

Since the interfacial tension $\gamma_{o w}$ of the system hexadecane-water with a value of $50-52 \mathrm{mN} / \mathrm{m}$ is higher than that of the system toluene-water $(36.4 \mathrm{mN} / \mathrm{m})$, the calculated energy required to remove the particles from the interface is about 1.4 times higher for the system using hexadecane. The stability of an emulsion formed with a 0.10 wt- $\%$ EMG900 in hexadecane suspension and 5 vol- $\%$ of water can be obtained from figure 8 where optical micrographs taken over a total period of seven days are shown. The size distribution of the droplets in all images is very similar and even after seven days droplets with a diameter of $10 \mu \mathrm{m}$ are present. From this observation it can be concluded that the emulsion is stable since there is no 
or very little coalescence taking place.

a)

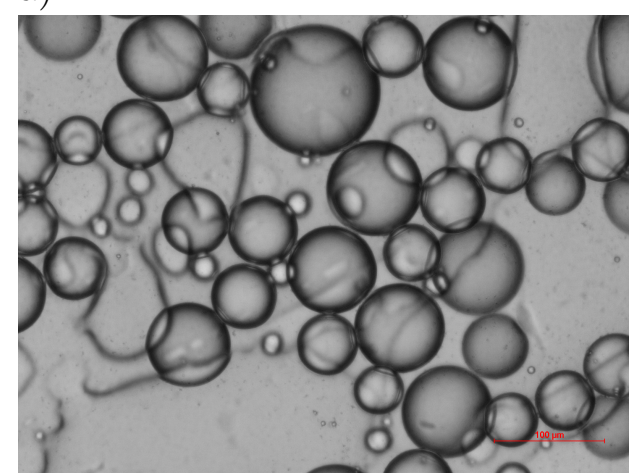

c)

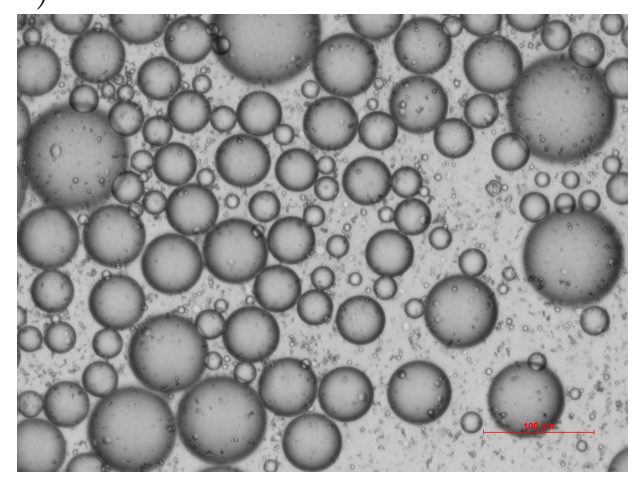

b)

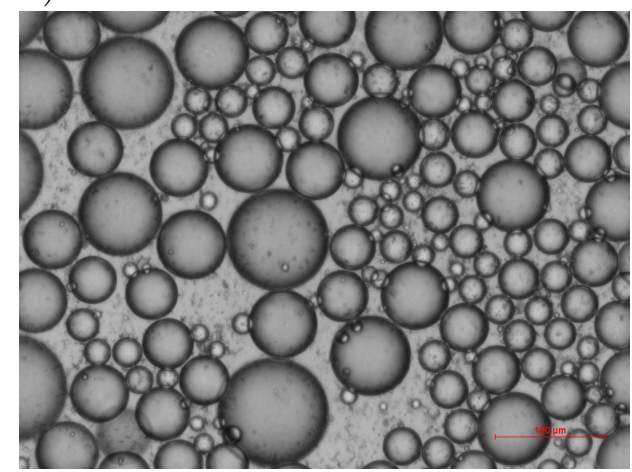

d)

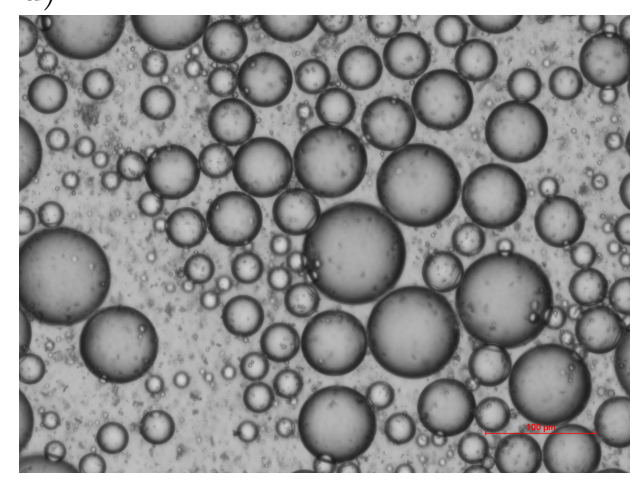

Figure 8. Optical micrographs of 5 vol- $\%$ water in hexadecane emulsion with 0.10 wt-\% EMG900 directly after formation (a), after 24 hours (b), after four days (c) and after seven days (d)

Besides the high stability the use of hexadecane is advantageous in terms of the process safety. It is not a health hazard to personnel working and increases the inherent process safety because of the higher flash point and reduced flammability.

As mentioned before an easy control of the magnetization of the emulsion droplets and capsules is to position a rod magnet next to the vial and watch if any attraction can be observed. The capsules formed with $0.10 \mathrm{wt}$ \% EMG900 particles in both hexadecane and toluene showed a behaviour as seen in figure 9 .

The capsules are accumulated on the wall of the glass vial right next to the spot where the rod magnet was placed. The magnet has been slightly moved away from the vial for imaging purposes, but is can be seen that the capsules still stay 


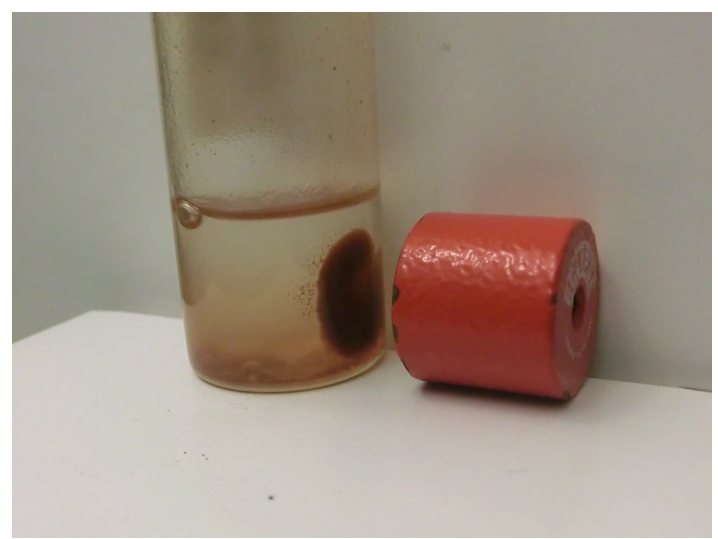

Figure 9. Photograph of a vial containing capsules produced from an EMG900stabilized emulsion in hexadecane under influence of the magnetic field of a rod magnet

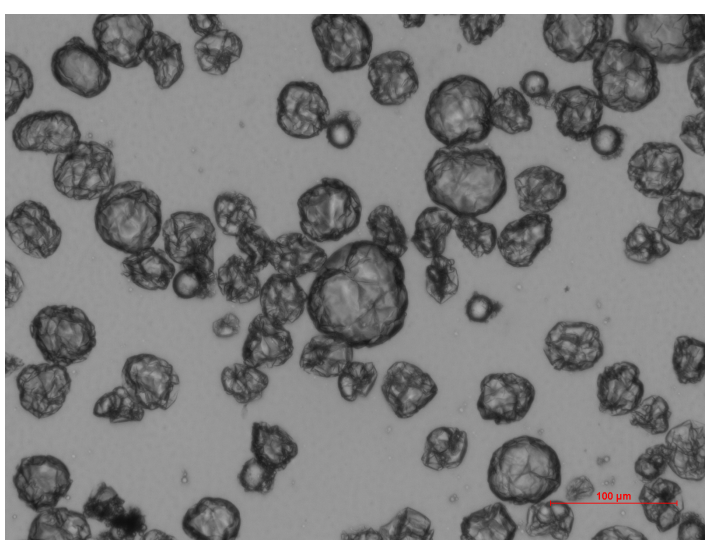

Figure 10. Optical micrograph of capsules in a sample attracted to a magnetic field made from 0.10 wt-\% EMG900 in hexadecane suspension with 5 vol- $\%$ water

at the place. The rest of the liquid is almost clear with only a small sediment. When a second magnet is put on the opposite side of the vial, there is another dark spot formed and the sediment is reduced. A sample has been taken from the dark region and analyzed with the optical microscope. Figure 10 shows that the dark spot completely consists of polymerized capsules with no free or agglomerated nanoparticles.

Besides the optical analysis of the capsules they have been examined with cryogenic SEM. A picture of a capsule obtained in hexadecane is shown in figure 11. Imaging conditions can be learned from the information section in the picture.

The feature with a total diameter of about $65 \mu \mathrm{m}$ shows a deformation in the upper part of the picture with a remnant of what seems to be a solid structure. The almost spherical capsule is based on EDS analysis constituted of water, which is shown by a high oxygen peak. The remnant structure on top is thought to be a part of the wall of the capsule, which has been damaged in the freezing process.

Normal mode SEM has been conducted on the sample additionally to cryogenic SEM. A drop of the sample was dried on an aluminum plate for 24 hours in 


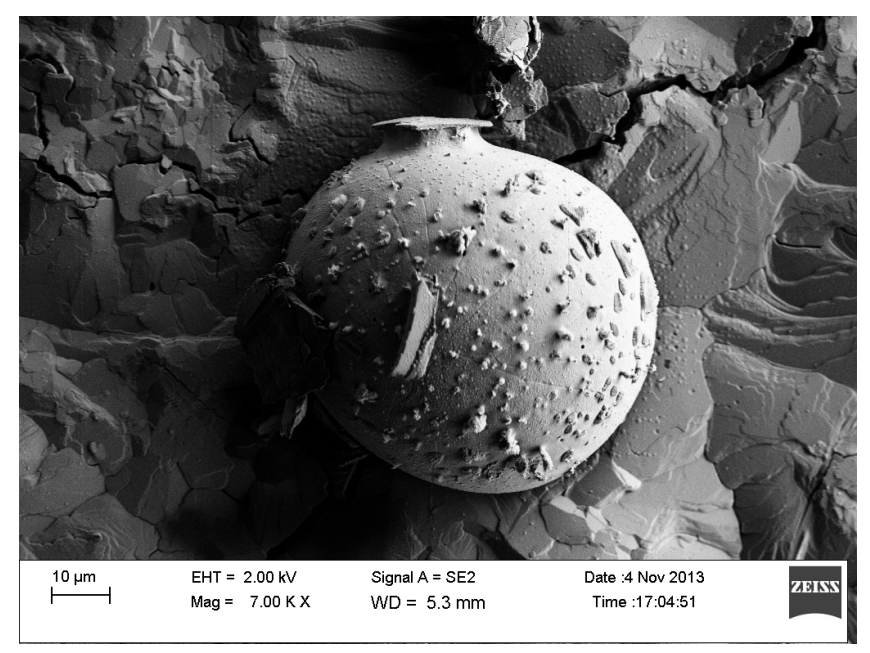

Figure 11. Cryogenic SEM image of a capsule produced in water in hexadecane emulsion using with $0.10 \mathrm{wt}-\%$ EMG900 nanoparticles and three hours reaction time

a vacuum oven at $95^{\circ} \mathrm{C}$. An electron image of a dried capsule formed in a 3-hour polymerization process in w/o-emulsion with $0.10 \mathrm{wt}-\%$ EMG900 nanoparticles in the continuous phase is given in figure 12. It can be seen that the feature lost its circular shape, which can be explained with the evaporation of the water in the core and the collapse of the polymer shell.

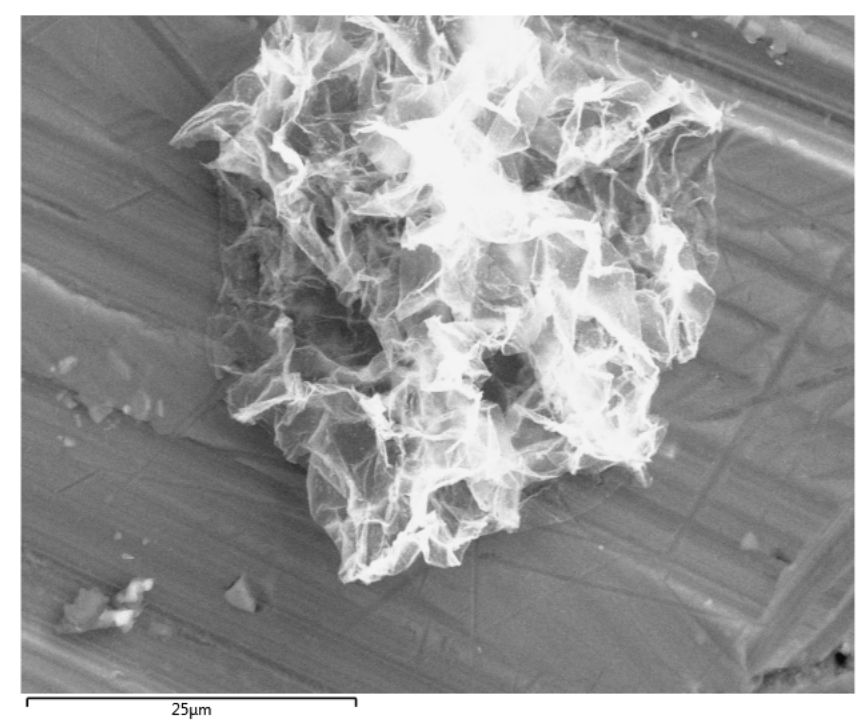

Figure 12. SEM image of a dried capsule produced from water in hexadecane emulsion using 0.10 wt-\% EMG900 nanoparticles and three hours reaction time 
In order to verify that the structure in figure 12 is a dried capsule EDS has been performed. Figure 13 shows the signal mapping data for iron and carbon. Both images give clear evidence that the structure is a capsule and that the emulsion has been stabilized with iron oxide nanoparticles. The iron signal comes from the iron oxide on the surface of the droplets and the carbon signal is generated by the polyurea shell wall.
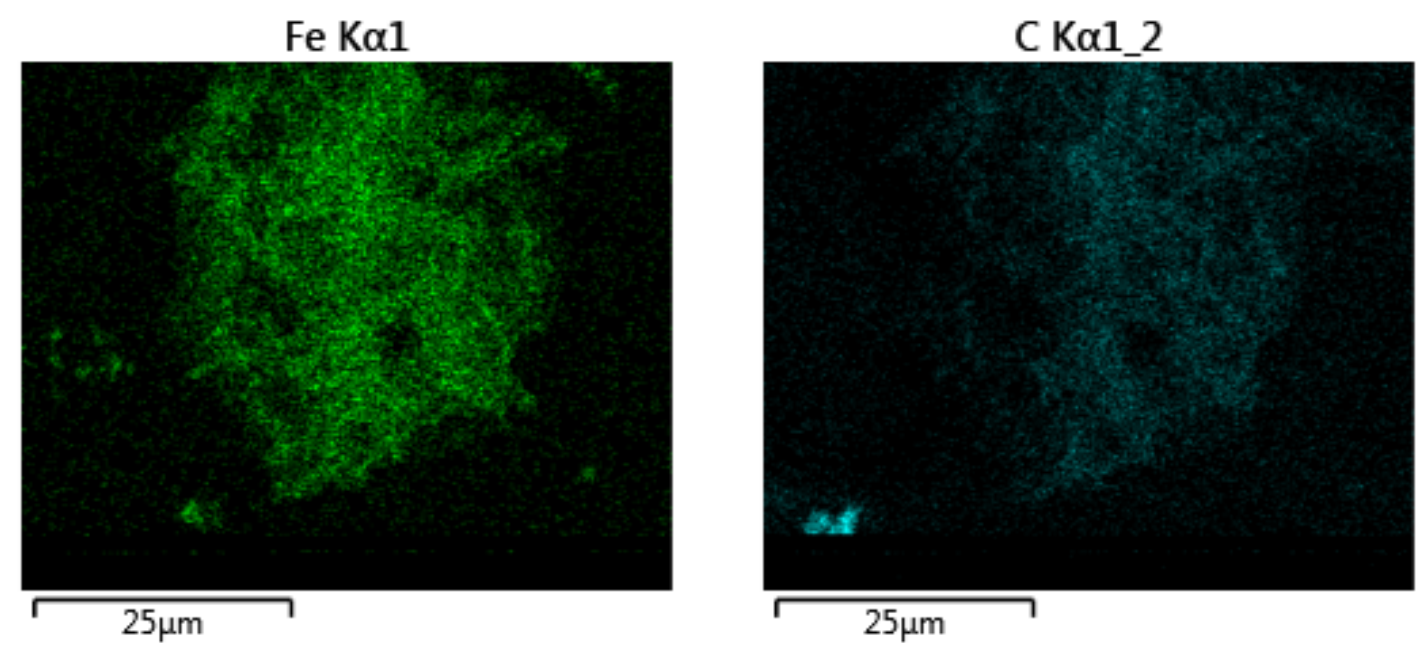

Figure 13. EDS mapping image of the $K \alpha$-signal of iron (left) and carbon (right) of a dried polyurea capsule

\subsection{Introduction of Calcium Nitrite into the system}

Initial experiments with calcium nitrite in the aqueous phase showed that salt concentrations of $0.10 \mathrm{M}, 0.52 \mathrm{M}$ and $1.04 \mathrm{M}$ did not lead to a sufficient emulsification of the water. An example of the result using 1.04 M CNI is given in figure 14 . It can be seen that only very little of the water volume has been emulsified as the lower right half of the image is covered by a big water drop and only few very small droplets can be observed. Results for $0.10 \mathrm{M}$ calcium nitrite were better, but still did no show emulsification comparable to plain water in the dispersed phase. Based on these observations it has been concluded that the salt affects the nanoparticles 
in the oil phase when the particles and the ions collide at the w/o-interface. A possible reason for this behavior might be that the particles' wettability changes so that they do not stay at the interface but form aggregates and stay in the bulk oil phase.

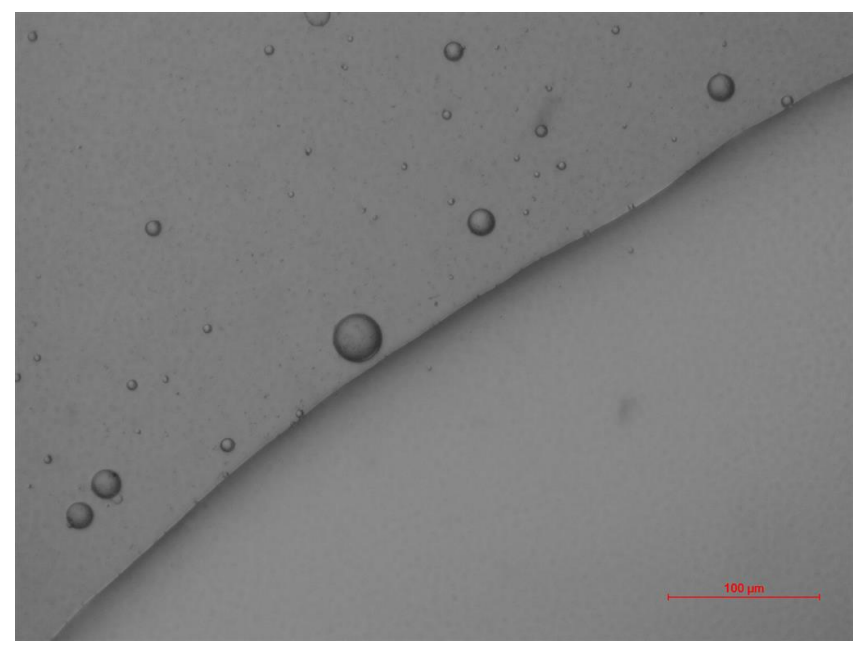

Figure 14. Optical micrograph of an emulsion with $1.04 \mathrm{M}$ calcium nitrite in water and $0.10 \mathrm{wt}-\%$ EMG900 in hexadecane. Lower right half and small droplets are water

To counteract this behavior a series of experiments have been carried out with different additional constituents in the water phase with varying concentrations as shown in table 3. The hydrophilic EMG700 particles are stabilized with an anionic surfactant. It was expected that the positive calcium ions would shield the negative charges on the particle surface and thereby decrease the wettability of the particles. With the correct salt concentration it could even be possible that these particles stabilize a w/o-emulsion. A similar mechanism was intended for carbon black particles, which have carboxylic groups on the surface. The citric acid (CA) was introduced to the system as a chelating agent as described by Saha et al. [1] to form complexes with the $\mathrm{Ca}^{2+}$ ion. The consumption of calcium ions does not pose a risk to the corrosion inhibiting mechanism since the nitrite ion is the active component as expressed in equation 2. The only successful emulsification was 
observed for the experiments using $0.10 \mathrm{M} \mathrm{CNI}$ and $0.005 \mathrm{M} \mathrm{CA}$. The following encapsulation lead to capsules as shown in figure 15 (left).

Table 3. Different compositions of oil and water phase in experiments to overcome emulsification problems with calcium nitrite (CNI). Adding of hydrophilic particles (EMG700), citric acid (CA), and carbon black particles (CB)

\begin{tabular}{r|rrrrr}
\hline Oil Phase & \multicolumn{5}{|c}{ Aqueous Phase } \\
\hline EMG900 [wt-\%] & volume [\%] & EMG700 [wt-\%] & CNI [M] & CA [M] & CB [wt-\%] \\
\hline 0.15 & 33 & 0.050 & 0.010 & - & - \\
0.15 & 28 & 0.050 & 0.150 & - & - \\
0.10 & 5 & - & 0.100 & 0.0050 & 0.0125 \\
0.10 & 5 & 0.025 & 0.100 & 0.0050 & - \\
0.10 & 5 & - & 0.100 & - & 0.01 \\
- & 5 & 0.100 & 0.050 & - & - \\
- & 20 & 0.100 & 0.002 & - & - \\
0.10 & 5 & - & 0.100 & 0.0050 & - \\
0.10 & 2 & - & 0.150 & 0.0075 & - \\
0.10 & 2 & - & 0.100 & 0.0050 & - \\
\hline
\end{tabular}
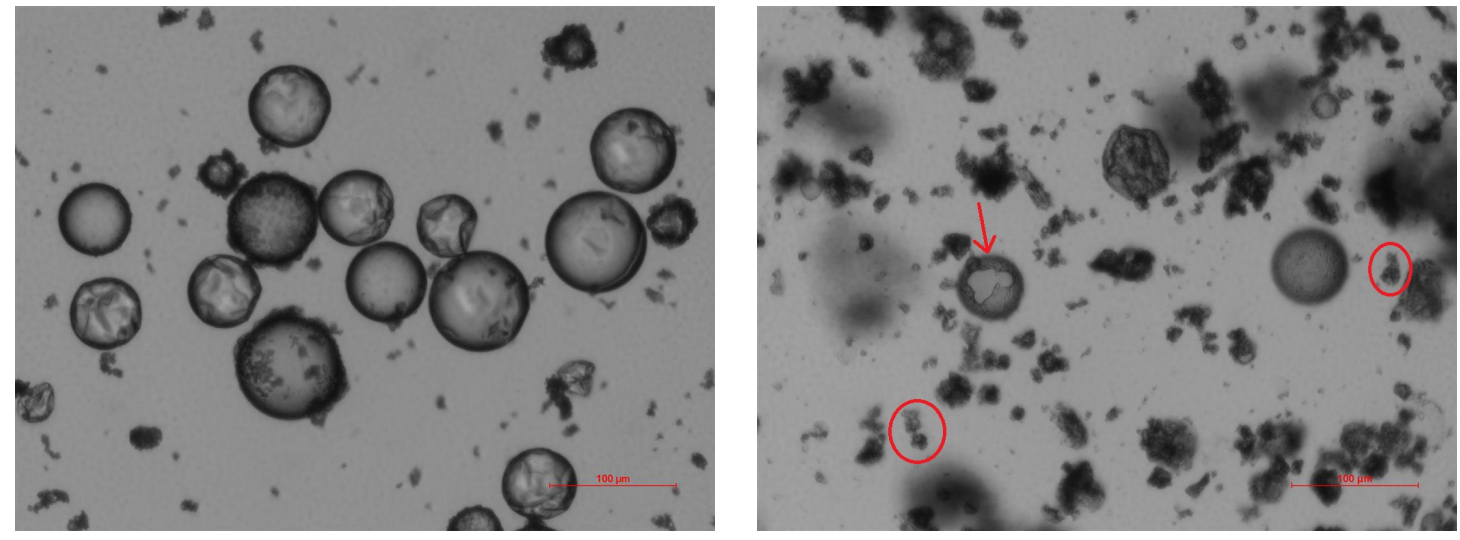

Figure 15. Optical micrographs of capsules in mixtures of water containing $0.1 \mathrm{M}$ calcium nitrite and $0.005 \mathrm{M}$ citric acid in hexadecane with 0.10 wt-\% EMG900 with different volume ratios of the dispersed phase and reaction time. Left: 2 vol-\%, $60 \mathrm{~min}$ and right: 5 vol- $\%$, $180 \mathrm{~min}$

On the surface of some of the capsules particles, that seem to be in some sort of small aggregates, can be seen as well as in the surrounding oil phase. For this experiment special attention was given to the stirring speed by completely avoiding deviations towards higher values of rpm, which are relatively common 
due to inconstant air pressure in the supply system. Also the encapsulation was stopped after 60 minutes. In a previous experiment over 180 minutes with regularly increasing stirring speed capsules that looked like a part of the shell wall has been broken off could be observed (fig 15, right, arrow). There are also features that can be interpreted as polymer pieces (encircled). The added citric acid leads to a decrease of the $\mathrm{pH}$ value, which in turn may destabilize the passive layer on the steel reinforcement. Since the ratio of calcium nitrite-to-citric acid concentrations is 20 and the ratio of nitrite ions to hydronium ions $\left(\mathrm{H}_{3} \mathrm{O}^{+}\right)$is approximately 13 the corrosion inhibiting capacity is still expected to be present. Additionally it has to be mentioned that organic acids such as citric acid are used for anodic passivation of steels [2] and acid solution is used in acid pickling and descaling of steels [3] even though inhibitors are used in that process [2]. 


\subsection{Conclusion}

It has been shown that the concept of producing polyurea capsules based on water in oil emulsion that are stabilized with nanoparticles is successful. Magnetic iron nanoparticles are used in this process and the obtained capsules show magnetic susceptibility, which makes them useful for the desired application in targeted placement on rebars in reinforced concrete. Additionally, the aromatic solvent toluene, serving as continuous phase, could be successfully replaced by the much less hazardous aliphatic hydrocarbon hexadecane, which reduces risks of the process tremendously. Furthermore calcium nitrite has been included into the aqueous droplets so that corrosion inhibition can be obtained.

\section{List of References}

[1] A. Saha, J. Lee, S. M. Pancera, M. F. Bräeu, A. Kempter, A. Tripathi, and A. Bose, "New insights into the transformation of calcium sulfate hemihydrate to gypsum using time-resolved cryogenic transmission electron microscopy," Langmuir, vol. 28, no. 30, pp. 11 182-11187, 2012.

[2] T. A. Richardson, R. A. Cottis, and L. L. Shreir, Shreir's corrosion, 4th ed. Amsterdam and London: Elsevier, 2010.

[3] M. Finšgar, "Galvanic series of different stainless steels and copper- and aluminium-based materials in acid solutions," Corrosion Science, vol. 68, no. 0, pp. 51-56, 2013. [Online]. Available: http://www.sciencedirect.com/ science/article/pii/S0010938X12005161 


\section{CHAPTER 4}

\section{Future Work}

For future work, the options presented in this outlook should be considered to be implemented in experiments.

Magnetic nanoparticles allow hyperthermia if they have superparamagnetic properties. This could be used for local heating of the droplet surface by applying a pulsating magnetic field to the emulsion. This would decrease the possibility of random reaction of monomer within the solution by reducing the overall temperature and the interrelated reaction rate. Therefore it is expected that the encapsulation process can be achieved in less time.

In the present work only a small amount of calcium nitrite as corrosion inhibitor could be encapsulated using an acid in the aqueous phase, which affects steel corrosion to some extent. Hence an optimization of the system is needed to evaluate the need of that acid. In order to reach full benefits for the application the healing agent sodium silicate has to be included in the capsules to reduce the enhance self-healing properties of the concrete matrix in close proximity to the reinforcement.

A procedure to simulate the application to place the capsules on the surface of rebars in concrete matrix has to be developed. Mortar samples have to be produced with embedded steel wires. A magnetic field around the wire could be obtained by running an electric current through them. Pouring the capsules over the wires should be sufficient to attract them and lead them to the wire's surface. 


\section{BIBLIOGRAPHY}

Abramson, S., Safraou, W., Malezieux, B., Dupuis, V., Borensztajn, S., Briot, E., and Bée, A., "An eco-friendly route to magnetic silica microspheres and nanospheres," Journal of Colloid and Interface Science, vol. 364, no. 2, pp. 324-332, 2011.

Andrade, C., Alonso, C., and Molina, F. J., "Cover cracking as a function of bar corrosion: Part i-experimental test," Materials and Structures, vol. 26, no. 8, pp. 453-464, 1993.

Berke, N. S. and Hicks, M. C., "Predicting long-term durability of steel reinforced concrete with calcium nitrite corrosion inhibitor," Corrosion Inhibitors, vol. 26, no. 3, pp. 191-198, 2004.

Bhattacharyya, T., "Self healing in concrete materials," Master's thesis, University of Rhode Island, Kingston RI, 2011.

Bhushan, B., "Biomimetics: lessons from nature-an overview," Philosophical Transactions of the Royal Society A: Mathematical, Physical and Engineering Sciences, vol. 367, no. 1893, pp. 1445-1486, 2009.

Biczók, I., Concrete corrosion and concrete protection, 3rd ed. New York: Chemical Pub. Co., 1967.

Binks, B. P. and Lumsdon, S. O., "Effects of oil type and aqueous phase composition on oil-water mixtures containing particles of intermediate hydrophobicity," Physical Chemistry Chemical Physics, vol. 2, no. 13, pp. 8622-8631, 2000 .

Binks, B. P. and Lumsdon, S. O., "Influence of particle wettability on the type and stability of surfactant-free emulsions $\dagger$," Langmuir, vol. 16, no. 23, pp. 8622-8631, 2000.

Binks, B. P., "Particles as surfactants- similarities and differences," Current Opinion in Colloid \& Interface Science, vol. 7, no. 1-2, pp. 21-41, 2002.

Burgdorf, T., Packroff, R., Apel, P., and Meyer-Plath Asmus, "1. bilanz zur gemeinsamen Forschungsstrategie der Ressortforschungseinrichtungen des Bundes "Nanotechnologie - Gesundheits- und Umweltrisiken von Nanomaterialien" (2007 - 2011)," 2013.

Cabrera, J., "Deterioration of concrete due to reinforcement steel corrosion," Cement and Concrete Composites, vol. 18, no. 1, pp. 47-59, 1996. 
Caré, S., Nguyen, Q., L'Hostis, V., and Berthaud, Y., "Mechanical properties of the rust layer induced by impressed current method in reinforced mortar," Cement and Concrete Research, vol. 38, no. 8-9, pp. 1079-1091, 2008.

Chen, M.-F., Lin, Y.-P., and Cheng, T.-J., "Public attitudes toward nanotechnology applications in taiwan," Technovation, vol. 33, no. 2-3, pp. 88-96, 2013.

Chevalier, Y. and Bolzinger, M.-A., "Emulsions stabilized with solid nanoparticles: Pickering emulsions," Colloids and Surfaces A: Physicochemical and Engineering Aspects, 2013.

Courland, R., Concrete planet: The strange and fascinating story of the world's most common man-made material. Amherst N.Y.: Prometheus Books, 2011.

Datta, R. and Jaitawat, S. S., "Nanotechnology - the new frontier of medicine," Medical Journal Armed Forces India, vol. 62, no. 3, pp. 263-268, 2006.

Eastoe, J. and Warne, B., "Nanoparticle and polymer synthesis in microemulsions," Current Opinion in Colloid 83 Interface Science, vol. 1, no. 6, pp. 800-805, 1996.

Estes, A. C. and Frangopol, D. M., "Minimum expected cost-oriented optimal maintenance planning for deteriorating structures: application to concrete bridge decks," Reliability Engineering 83 System Safety, vol. 73, no. 3, pp. 281-291, 2001.

Finšgar, M., "Galvanic series of different stainless steels and copper- and aluminium-based materials in acid solutions," Corrosion Science, vol. 68, no. 0, pp. 51-56, 2013. [Online]. Available: http://www.sciencedirect.com/ science/article/pii/S0010938X12005161

González, J., Andrade, C., Alonso, C., and Feliu, S., "Comparison of rates of general corrosion and maximum pitting penetration on concrete embedded steel reinforcement," Cement and Concrete Research, vol. 25, no. 2, pp. 257264, 1995.

Gupta, A. K. and Gupta, M., "Synthesis and surface engineering of iron oxide nanoparticles for biomedical applications," Biomaterials, vol. 26, no. 18, pp. 3995-4021, 2005.

Ingram, D. R., Kotsmar, C., Yoon, K. Y., Shao, S., Huh, C., Bryant, S. L., Milner, T. E., and Johnston, K. P., "Superparamagnetic nanoclusters coated with oleic acid bilayers for stabilization of emulsions of water and oil at low concentration," Journal of Colloid and Interface Science, vol. 351, no. 1, pp. 225-232, 2010. 
Jonkers, H. M., Thijssen, A., Muyzer, G., Copuroglu, O., and Schlangen, E., "Application of bacteria as self-healing agent for the development of sustainable concrete," Special Issue: BioGeoCivil Engineering, vol. 36, no. 2, pp. 230-235, 2010.

Kiani, K. and Shodja, H. M., "Prediction of the penetrated rust into the microcracks of concrete caused by reinforcement corrosion," Applied Mathematical Modelling, vol. 35, no. 5, pp. 2529-2543, 2011.

Kim, S.-H. and Weitz, D. A., "One-step emulsification of multiple concentric shells with capillary microfluidic devices," Angewandte Chemie, vol. 123, no. 37, pp. 8890-8893, 2011.

Király, Z., "Colloid chemistry: Lecture 13: Emulsions," 10/09/2013. [Online]. Available: http://koll1.chem.u-szeged.hu/colloids/staff/zoli/Pharmacy/ Lecture\%2013.pdf

Królikowski, A. and Kuziak, J., "Impedance study on calcium nitrite as a penetrating corrosion inhibitor for steel in concrete," ELECTROCHEMICAL IMPEDANCE SPECTROSCOPY, vol. 56, no. 23, pp. 7845-7853, 2011.

Kwade, A., "Formulierungstechnik - Emulsionen," 06/21/2012, class presentation.

Lan, Q., Liu, C., Yang, F., Liu, S., Xu, J., and Sun, D., "Synthesis of bilayer oleic acid-coated fe3o4 nanoparticles and their application in ph-responsive pickering emulsions," Journal of Colloid and Interface Science, vol. 310, no. 1, pp. 260-269, 2007.

Liu, G., Yang, H., Zhou, J., Law, S.-J., Jiang, Q., and Yang, G., "Preparation of magnetic microspheres from water-in-oil emulsion stabilized by block copolymer dispersant," Biomacromolecules, vol. 6, no. 3, pp. 1280-1288, 2005.

Mehta, P. K. and Monteiro, P., Concrete: Structure, properties, and methods, 2nd ed., ser. Prentice-Hall international series in civil engineering and engineering mechanics. Englewood Cliffs and N.J: Prentice Hall, 1993.

Melle, S., Lask, M., and Fuller, G. G., "Pickering emulsions with controllable stability," Langmuir, vol. 21, no. 6, pp. 2158-2162, 2005.

Miyazaki, K. and Islam, N., "Nanotechnology systems of innovation-an analysis of industry and academia research activities," Technovation, vol. 27, no. 11, pp. 661-675, 2007.

Morgan, D., "Compatibility of concrete repair materials and systems," Construction and Building Materials, vol. 10, no. 1, pp. 57-67, 1996. 
Nawy, E. G., Reinforced concrete: A fundamental approach, 5th ed., ser. PrenticeHall international series in civil engineering and engineering mechanics. Upper Saddle River and N.J: Pearson Education, 2005.

Neuser, S., Michaud, V., and White, S. R., "Improving solvent-based self-healing materials through shape memory alloys," Polymer, vol. 53, no. 2, pp. 370-378, 2012.

Ngala, V. T., Page, C. L., and Page, M. M., "Corrosion inhibitor systems for remedial treatment of reinforced concrete. part 1: calcium nitrite," Corrosion Science, vol. 44, no. 9, pp. 2073-2087, 2002.

Pelletier, M., "Self-healing concrete," Master's thesis, University of Rhode Island, Kingston RI, 2010.

Pickering, S. U., "Emulsions," Journal of the Chemical Society, Transactions, vol. 91, pp. 2001-2021, 1907.

Qiao, X., Zhou, J., Binks, B. P., Gong, X., and Sun, K., "Magnetorheological behavior of pickering emulsions stabilized by surface-modified fe3o4 nanoparticles," Colloids and Surfaces A: Physicochemical and Engineering Aspects, vol. 412, pp. 20-28, 2012.

Rampf, M., Speck, O., Speck, T., and Luchsinger, R. H., "Self-repairing membranes for inflatable structures inspired by a rapid wound sealing process of climbing plants," Journal of Bionic Engineering, vol. 8, no. 3, pp. 242-250, 2011.

Ramsden, W., "Separation of solids in the surface-layers of solutions and 'suspensions' (observations on surface-membranes, bubbles, emulsions, and mechanical coagulation). - preliminary account," Proceedings of the Royal Society of London, vol. 72, no. 477-486, pp. 156-164, 1903.

Reinke, S. K., "Polyurea/polyurethane microcapsules based self healing concrete," Master's thesis, University of Rhode Island, Kingston RI, 2012.

Richardson, T. A., Cottis, R. A., and Shreir, L. L., Shreir's corrosion, 4th ed. Amsterdam and London: Elsevier, 2010.

Saha, A., Lee, J., Pancera, S. M., Bräeu, M. F., Kempter, A., Tripathi, A., and Bose, A., "New insights into the transformation of calcium sulfate hemihydrate to gypsum using time-resolved cryogenic transmission electron microscopy," Langmuir, vol. 28, no. 30, pp. 11 182-11187, 2012.

Saihi, D., Vroman, I., Giraud, S., and Bourbigot, S., "Microencapsulation of ammonium phosphate with a polyurethane shell. part ii. interfacial polymerization technique," Reactive and Functional Polymers, vol. 66, no. 10, pp. 1118-1125, 2006. 
Sideris, K. K. and Savva, A. E., "Durability of mixtures containing calcium nitrite based corrosion inhibitor," Cement and Concrete Research in Greece, vol. 27, no. 2, pp. 277-287, 2005.

Song, H.-W. and Saraswathy, V., "Corrosion monitoring of reinforced concrete structures - a review," International Journal of Electrochemical Science, vol. 2, no. $1,2007$.

Song, Y.-K., Jo, Y.-H., Lim, Y.-J., Cho, S.-Y., Yu, H.-C., Ryu, B.-C., Lee, S.I., and Chung, C.-M., "Sunlight-induced self-healing of a microcapsule-type protective coating," ACS Applied Materials $\&$ Interfaces, vol. 5, no. 4, pp. 1378-1384, 2013.

Teja, A. S. and Koh, P.-Y., "Synthesis, properties, and applications of magnetic iron oxide nanoparticles," Progress in Crystal Growth and Characterization of Materials, vol. 55, no. 1-2, pp. 22-45, 2009.

Val, D. V. and Stewart, M. G., "Life-cycle cost analysis of reinforced concrete structures in marine environments," Structural Safety, vol. 25, no. 4, pp. 343$362,2003$.

van Tittelboom, K., Belie, N. d., Muynck, W. d., and Verstraete, W., "Use of bacteria to repair cracks in concrete," Cement and Concrete Research, vol. 40, no. 1, pp. 157-166, 2010.

White, S. R., Sottos, N. R., Geubelle, P. H., Moore, J. S., Kessler, M. R., Sriram, S. R., Brown, E. N., and Viswanathan, S., "Autonomic healing of polymer composites," Nature, vol. 409, no. 6822, pp. 794-797, 2001.

Wu, D. Y., Meure, S., and Solomon, D., "Self-healing polymeric materials: A review of recent developments," Progress in Polymer Science, vol. 33, no. 5, pp. 479-522, 2008.

Wu, M., Johannesson, B., and Geiker, M., "A review: Self-healing in cementitious materials and engineered cementitious composite as a self-healing material," Construction and Building Materials, vol. 28, no. 1, pp. 571-583, 2012.

Zhao, Y., Ren, H., Dai, H., and Jin, W., "Composition and expansion coefficient of rust based on x-ray diffraction and thermal analysis," Corrosion Science, vol. 53, no. 5, pp. 1646-1658, 2011. 